\title{
State of the Art of the Techniques for Grid Forming Inverters to Solve the Challenges of Renewable Rich Power Grids
}

\author{
Efaf Bikdeli $^{1}$, Md. Rabiul Islam ${ }^{2, *(\mathbb{D}, \text { Md. Moktadir Rahman }}{ }^{3}$ and Kashem M. Muttaqi ${ }^{2}$ \\ 1 Department of Electrical and Computer Engineering, Babol Noshirvani University of Technology, \\ Babol 47148-71167, Iran; efafbikdeli@gmail.com \\ 2 School of Electrical, Computer and Telecommunications Engineering, Faculty of Engineering and Information \\ Sciences, University of Wollongong, Wollongong, NSW 2522, Australia; kashem@uow.edu.au \\ 3 Energy \& Grid Division, Ingeteam Australia Pty Ltd., Wollongong, NSW 2500, Australia; \\ moktadir2020@gmail.com \\ * Correspondence: mrislam@uow.edu.au; Tel.: +61-2-4221-3624
}

check for updates

Citation: Bikdeli, E.; Islam, M.R.; Rahman, M.M.; Muttaqi, K.M. State of the Art of the Techniques for Grid Forming Inverters to Solve the Challenges of Renewable Rich Power Grids. Energies 2022, 15, 1879 https://doi.org/10.3390/en15051879

Academic Editor: Paolo Mattavelli

Received: 30 January 2022

Accepted: 2 March 2022

Published: 3 March 2022

Publisher's Note: MDPI stays neutral with regard to jurisdictional claims in published maps and institutional affiliations.

Copyright: (C) 2022 by the authors. Licensee MDPI, Basel, Switzerland. This article is an open access article distributed under the terms and conditions of the Creative Commons Attribution (CC BY) license (https:// creativecommons.org/licenses/by/ $4.0 /)$.

\begin{abstract}
To mitigate the fast-growing demand of electrical energy, the use of renewable energy resources, e.g., solar and wind, can offer an environmentally friendly and sustainable solution. Due to their intermittent nature, the grid connected operation of renewable energy resources provides a better performance compared to the standalone operation. However, the massive penetration of power electronic inverter/converter-interfaced renewable resources in power systems introduces new issues, such as voltage and frequency instabilities, because of their inherent low inertia properties. As a consequence, these issues may lead to serious problems, such as system blackouts. Therefore, there is an immediate demand to solve these new issues and ensure the normal performance of the power system with the large penetration of renewable energy resources. To achieve this, grid connected inverters/converters are designed to address these problems and behave as synchronous generators, which is possible with grid forming (GFM) inverters/converters concepts. This paper reviews the recent advancement of GFM converters for solving emerging issues related to the renewable rich power grids. It also provides a comprehensive review on frequency deviations and power system stability issues in low-inertia systems and recent advancements in control methods for harmonic mitigation. It is expected that this paper will help the research community to enhance the technology further to solve the challenges in renewable rich power grids.
\end{abstract}

Keywords: renewable energy resources; grid integration; grid forming converters; rate of change of frequency; low inertia; virtual inertia; system stability; harmonic mitigation; black start capability

\section{Introduction}

Electrical energy is the most common and widely used form of energy as it has many advantages, e.g., easy to transform and transport. The generation of electrical energy from traditional sources, e.g., coal, oil, and gas, produces vast $\mathrm{CO}_{2}$ gases, which heavily affect the environment and consequently destroy the sustainability of the world. On the other hand, the generation of electrical energy from renewable energy resources, e.g., solar and wind, can keep the environment sustainable without any emission of $\mathrm{CO}_{2}$. Many countries have already set their target to generate a significant percentage of electrical energy from renewable resources to keep the environment sustainable. Many governments and industries are working closely to achieve the net-zero carbon emissions goal. In many countries, traditional fossil-fuel-based power plants are being replaced by renewable-energy-based power plants, e.g., solar photovoltaic and wind plants. Due to their intermittent nature, the grid connected operation of renewable energy resources provides a better performance compared to the standalone operation. Power electronic inverters/converters are the key components in interfacing renewable energy resources to the power grids. 
As more and more renewable resources are integrated into the power grids, electric power systems are experiencing a transition from a synchronous generator-based control to inverter/converter-based resources. Conventionally, converter-based sources have been working in the grid-following mode, as a current source in the system [1,2]. In this mode, ancillary services, such as steady-state voltage support through reactive power injection, fault ride through, dynamic voltage support, and primary frequency support in terms of droop and inertial response, are available [3-5]. However, these supports are not effective enough under a disturbance situation, because of problems, such as sensing and actuation delays, decreasing synchronous generation in weak grids, and challenges in the phase locked loop (PLL) and the rate of change of frequency measurement $[3,6-8]$. Due to the delay in frequency estimation and control response time in this mode, the concept of synthetic inertia cannot effectively limit the frequency derivative.

Grid-forming (GFM) converters are a reliable alternative for grid-following (GFL) converters, which behave as a controllable voltage source and create voltage and frequency in the system $[3,9,10]$. In the grid-forming mode, the converter is robustly synchronized to the grid and, in the case of any disturbance, without the need for a PLL, the problem is solved quickly [11]. In terms of frequency stability and short-term voltage stability, grid-forming has a superior dynamic behavior compared to GFL and synchronous machines [12-14]. Additionally, these are necessary for islanded operations and black start services [11]. Therefore, these converters are a promising method for the high penetration of renewable energy sources $[9,10,15]$ and have a number of system functionalities, such as superior synchronization in weak grid situations, stand-alone functions and decentralized power sharing of different sources in islanded operations, which is not possible in GFL modes [16]. Table 1 shows a comparison of GFL and GFM inverter in terms of their capabilities.

Table 1. Comparison of GFL and GFM inverter capabilities.

\begin{tabular}{cr}
\hline GFL & GFM \\
\hline Current source inverter & Voltage source inverter \\
\hline Controlling the current and phase angle & Controlling the voltage amplitude and frequency \\
\hline Following the grid & Adjusting voltage and frequency of the grid \\
\hline Controlling the active and reactive power & Balancing loads instantaneously \\
\hline- & Operating in islanded mode and weak grid condition \\
\hline- & Contribution to system inertia \\
\hline
\end{tabular}

This paper reviews the recent advancements of GFM converters for solving emerging issues related to renewable rich power grids. It also provides a comprehensive review on frequency deviations and power system stability issues, including resonance stability and converter-driven stability in low-inertia systems, and recent advancements in control methods, including the virtual impedance-based control method and the filtering method for harmonic mitigation.

This paper is organized as follows. First, the importance of limiting of the rate of change of frequency (RoCoF) in low-inertia power systems is discussed and different schemes for this purpose are reviewed in Section 2. After that, the black start capability of GFM converters is defined in Section 3. Power system stability problems based on different instability phenomena and current advanced methods are summarized in Section 4. Section 5 describes various control methods used for harmonic mitigation in GFM converters. Finally, the paper is summarized with a conclusion and future scope in Sections 6 and 7, respectively. 


\section{Rate of Change of Frequency in a Low-Inertia Power System}

With the high penetration of converter-interfaced renewables and the replacement of synchronous generators by them, the inertia of the modern power system is reduced. Consequently, there is a possibility that the grid frequency and RoCoF are increased compared to its normal operation range, which can cause problems, such as load shedding and system blackout [17]. Inertia represents the physical characteristic of the rotating machines to respond an immediate change in the active power output during any frequency change in the network. Therefore, increasing the inertia of the power system and limiting the RoCoF of the system are really important. To address the aforementioned problems, the work in [18] provides a synthetic inertia control with the ability of RoCoF mitigation and considers the inverter synchronization dynamics. The proposed controller is regulated to have a fast settling time without any oscillations.

In [19], a new frequency shaping control is proposed to control a GFM converter frequency of a low-inertia power system. In this study, the frequency dynamics of the system are modeled into a first-order one with acceptable steady-state frequency deviations and $\mathrm{RoCoF}$ after a sudden change in power. The first order frequency response of the system causes the system to reach its new steady-state without any frequency nadir. In [20], in order to emulate the inertia of synchronous generators and primary frequency control, a synchronous active power control strategy is proposed, which incorporates inertia emulation, damping and P-f droop control as an alternative to emulate the inertia characteristics of a synchronous machine.

Additionally, a virtual synchronous generator (VSG) with emulating the swing equation of a synchronous generator can provide inertia support for the system. This control scheme needs an energy storage system to limit the grid frequency deviations by providing active power continuously [21,22]. In [23], a hybrid energy storage system, including a superfast capacitor and a battery, is added to regulate the frequency of the VSG-based grid connected system. The superfast capacitor is responsible for suppressing high frequency power fluctuations by emulating the inertia of the system, and the battery is added to provide power support and mitigation of low frequency power fluctuations. Figure 1 shows the block diagram of the proposed power management strategy. The relevant Swing equation is given by:

$$
\Delta P_{g_{-} p u}+\Delta P_{d_{-} p u}=\Delta P_{i n_{-} p u}+\left(-2 H \frac{d \Delta f_{g_{-} p u}}{d t}\right)
$$

where $\Delta P_{g_{-} p u}$, and $\Delta P_{d_{-} p u}=D \Delta f_{g_{-} p u}$ are the power variation by the load and renewable energy sources, and the frequency dependent load, respectively; $\Delta f_{g_{-} p u}$ is the deviation of the system frequency; and $\mathrm{R}_{\mathrm{d}}$ and $\mathrm{H}$ are the droop coefficient and emulated system inertia, respectively. $\left(\Delta P_{i n_{p u}}+\left(-2 H \frac{d \Delta f_{g p u}}{d t}\right)\right)$ is the power utilized for load balancing and renewable energy source power changes, where the speed governor and turbine makes the changes of $\Delta P_{i n_{-} p u}$ slow by adjusting the time delay, and it should track the power reference provided by the frequency droop $-\Delta P_{r_{p u}}$, and $\left(-2 H \frac{d \Delta f_{g-p u}}{d t}\right)$ is the power generated by inertia emulation, which are considered as a slow changing expression to the battery and a fast varying expression to the superfast capacitor, respectively.

In [24], in order to limit the RoCoF and steady-state frequency deviation of the system in the absence of inertia response, a new scheme based on the energy storage system analysis with VSG control is proposed. In the paper, the capacity and energy capacity of the energy storage system are studied to provide the required power support in different frequency adjustment stages. In [25], a new extended VSG control scheme is proposed to improve the frequency support of the hybrid low-inertia system. This scheme provides inertia along with fast frequency response for the system by controlling the active power of the converter interfaced energy storage system and adding a fast frequency response block to the control system. 


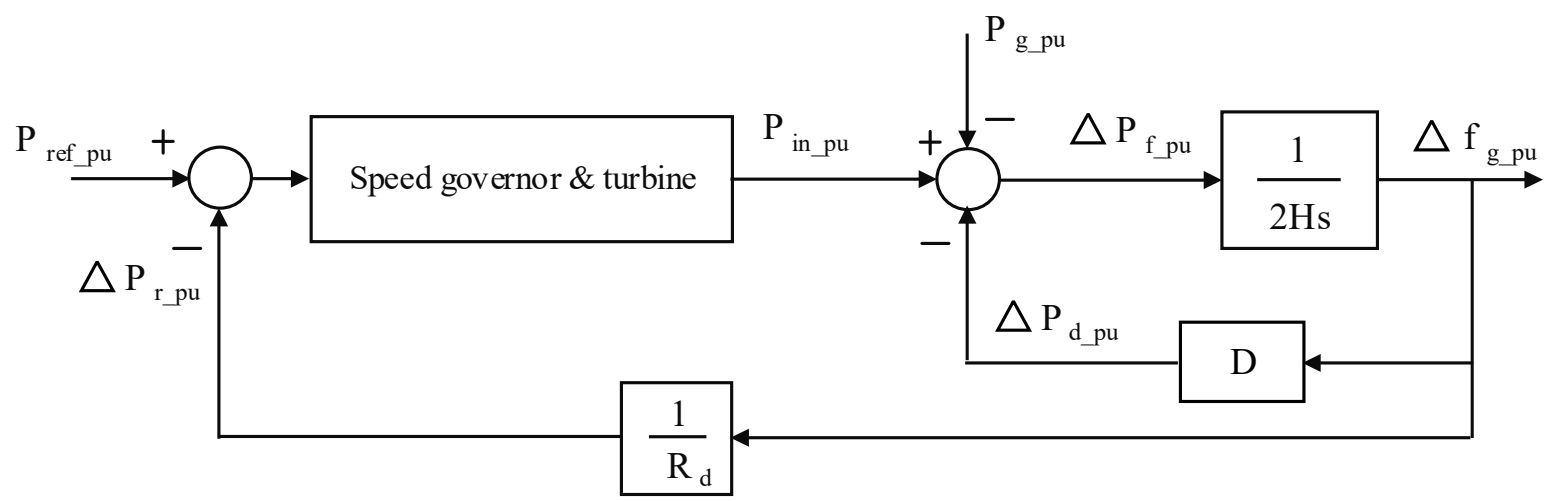

Figure 1. Block diagram of the proposed power management strategy in [23].

\section{Black Start Capability}

Due to growing penetration of the power electronic-converter-based generators and continuous displacement of the synchronous generators, the ability to restore the power system from an outage is reducing. This service is usually provided by the black-start units (e.g., diesel generators and small gas turbines) that can self-energize and are able to work as a voltage source to provide the required active and reactive power to energize the components that require high inrush currents (e.g., motors, transformers, and lines). The GFL converter requires an external grid and/or grid references to start up. Therefore, it cannot provide black start support.

With the advance of GFM, converters with renewable energy resources and interfacing battery energy storage can provide black start capability [26]. This is performed through a soft energization of the connected network, where voltage is linearly ramped up to eliminate the inrush current and harmonics of the transformers and motors. This slow voltage ramp up reduces the chances of tripping the protection relays due to a high inrush current and prevents harmonic overvoltage. The black start capability of four different grid forming control methods, e.g., droop, power synchronization, virtual synchronous machines (VSM), and matching under voltage and active power reference disturbances are compared in [27]. The study shows that VSM is superior to others in different disturbances. In [28], a modified VSM-based grid connected control using a ramping voltage reference for a black-start operation is proposed. A direct voltage control-based grid forming approach with the black-start capability of wind turbine control is proposed in [29]. However, all the above studies are limited to the small section of local distribution network restorations and are not tested for the large system restart process.

\section{Power System Stability}

Power system stability is another important problem related to power system performance, which can cause severe issues, such as blackouts with extraordinary losses [30]. Therefore, it becomes an outstanding aspect of research [31]. The classification of the traditional power systems based on the synchronous generator [32] needs to be redefined due to the high penetration of converter- or inverter-based generators into the grid. The rotor angle, frequency and voltage stabilities are significantly impacted by the increased penetration of the converter-based generators as the system inertia will be reduced due to the displacement of the synchronous generators by the converter-based generators. The reduction in the system inertia results in more faster and frequent frequency excursions, cause instability in the controls of converter-based generators. Likewise, the fast current injection from the converter-based generators move the voltage rapidly in the low-inertia grid, which can cause voltage stability issues. There are two new stability classifications that are considered in the power system stability, namely, resonance stability and converter-driven stability, and are shown in Figure 2 [33]. 


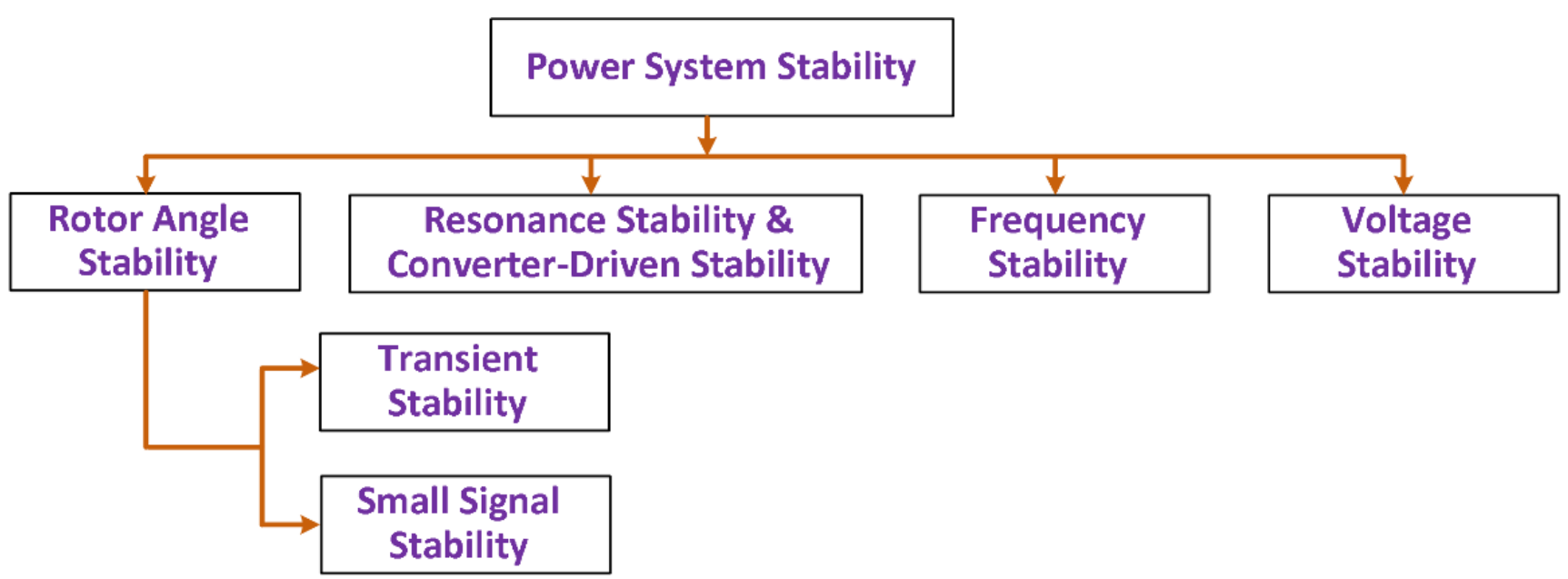

Figure 2. Different categories of power system stability.

\subsection{Rotor Angle Stability}

With the high penetration of low-inertia converter-based resources and the sensitivity of these converters to weak and faulty grids that threaten the synchronization stability of the system, various grid-synchronization methods have been proposed [34,35]. Some of them have analyzed the synchronization stability of the system under small disturbances (small-signal synchronization stability), while others have analyzed the transient stability of the system and proposed various stabilization methods.

\subsubsection{Transient Stability}

GFM converter control methods have attracted more attention due to their advantages over the GFL converter control methods in the case of weak and low-inertia power systems $[34,36]$. Although GFM converters can directly control the voltage and frequency, they cannot limit the converter current and fault-ride-through current in grid transient conditions, such as short circuit faults [37]. However, due to the low current rate of switches in these converters, it is important to use current limitations to limit overcurrent and protect switches during voltage drop events [38]. In order to achieve the current limitation, various control methods are used, such as changing the operation to the GFL mode [39,40], changing the voltage controller by adding an inner-current control loop [41,42], using virtual impedance $[43,44]$, among others. However, limiting the current with different approaches can affect the system stability and the GFM converters have to stay stable and synchronized with the grid after large disturbances, which is defined as the transient stability $[45,46]$.

In the literature, various methods are used to limit the fault currents. Limiting the inverter current may lead to a poor post-fault transient, and improper adjustment of the converter controller can also lead to oscillatory transients and overshoots in post-fault responses [39,47]. However, in some cases, only current limitation is used, while in other cases oscillations and post-fault recovery techniques are adopted. In some papers, the large disturbances that do not stimulate the system overcurrent limitation are considered.

Table 2 summarizes the different methods for transient stability improvement in GFM converters on the basis of three categories, i.e., current limitation, current limitation along with post-fault improvement, and without overcurrent stimulation. 
Table 2. Methods used for transient stability improvement in GFM converters.

\begin{tabular}{|c|c|}
\hline Categories & Methods \\
\hline \multirow{4}{*}{ Current limitation } & Limiting the converter output voltage [48] \\
\hline & Using circular current limiter in unified virtual oscillator control [49] \\
\hline & Considering the impact of current reference angle [50] \\
\hline & Using virtual admittance [51] \\
\hline \multirow{3}{*}{$\begin{array}{l}\text { Current limitation along } \\
\text { with post-fault } \\
\text { improvement }\end{array}$} & Using virtual impedance and adaptive parameters of the droop controller [52] \\
\hline & Adjusting power references based on the voltage drop along with a virtual resistance [35] \\
\hline & Using adaptive virtual resistance according to the intensity of the post fault oscillations [53] \\
\hline \multirow{3}{*}{$\begin{array}{l}\text { Without overcurrent } \\
\text { stimulation }\end{array}$} & Mode adaptive power angle control scheme [54] \\
\hline & Improving the large signal angle stability by changing the internal voltage control [55] \\
\hline & Use of frequency deviation through a high pass filter in combination with active power control loop [56] \\
\hline
\end{tabular}

\section{A. Current Limitation}

The use of the current limitation increases the critical clearing angle, but the system depends on the fault duration, and if the fault is cleared after the critical clearing angle, the part of the system that is affected loses its synchronization with the rest of the system and becomes unstable. In [48], to solve the above mentioned problems, a new control method for the GFM converter under symmetric and asymmetric faults is proposed, which limits the current to the desired value by limiting the converter output voltage, and to stabilize the system. In this method, the current is not a fixed value and it changes based on the voltage change. Therefore, when the voltage decreases, the converter reactive power should be maximized to compensate for it, so the reactive current should be considered equal to the maximum value. According to Figure 3, the converter output voltage amplitude is limited to the saturated voltage, $\mathrm{E}_{\max }$, and due to the dependence of the voltage phase on the power converter reference, the power reference is limited. $\mathrm{P}$ and $\mathrm{Q}$ are the power at the point of common coupling (PCC) and $\mathrm{U}_{\mathrm{o}}$ is the nominal output voltage of the converter.
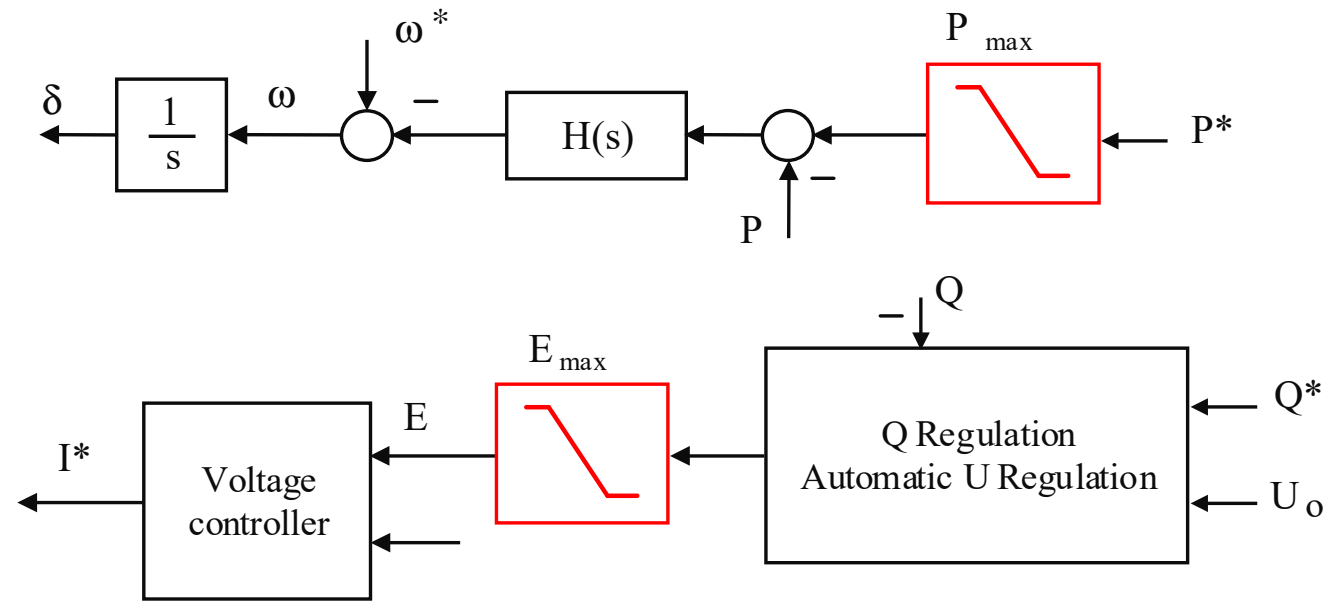

Figure 3. GFM converter control in voltage limiting mode, according to ( ${ }^{*}$ indicates reference value) [48].

In [49], the transient stability of the GFM converter based on unified virtual oscillator control (uVOC) is analyzed for both current-constrained and current-unconstrained fault situations under symmetrical AC faults. Since this method involves generating current reference in the synchronization loop, it is possible to apply current limiters without saturating the outer loop. When the output current of the converter extends beyond an overcurrent threshold, the controller operation changes to the current-constrained mode. 
In this condition, by using the circular limiter, the magnitude of the current reference is limited and keeps the angle unchanged. While in the current-unconstrained mode, fault current is limited through the GFM nature.

The transient stability of a GFM converter under a balanced voltage sag is analyzed in [50] using a current saturation algorithm and considering the role of the current reference angle. In the saturated mode, the calculation of the critical clearing angle (CCA) and the critical clearing time (CCT) are discussed and their role and duration of the overcurrent are then investigated to take the control back and keep the system stable. The other parameter used to enhance the transient stability of the GFM converter is the saturated current angle, while increasing this angle increases the system CCA and CCT, so the system has more time to clear the fault and back to its voltage control, but assigning the optimal angle value to ensure post-fault recovery to voltage control mode is really important. In the saturated operation mode, the active power is calculated as follows:

$$
P=P_{\text {max }_{S A T}} \cos (\delta-\varphi)
$$

Based on (2) and the positive angle, the CCA and CCT are increased, which means more time to clear the fault. Figure 4 shows the mechanism of operation of the converter under a voltage drop with and without considering the impact of $\varnothing$, where the green curve represents the saturated curve without considering $\varnothing$ and the red one represents the saturated curve considering $\varnothing$, where the $\delta_{\text {maxsat }}^{\varnothing}$ and $\delta_{\mathrm{cc}}^{\varnothing}$ are the maximum angle that the converter can touch and the critical clearing angle with considering the impact of $\varphi$, respectively.

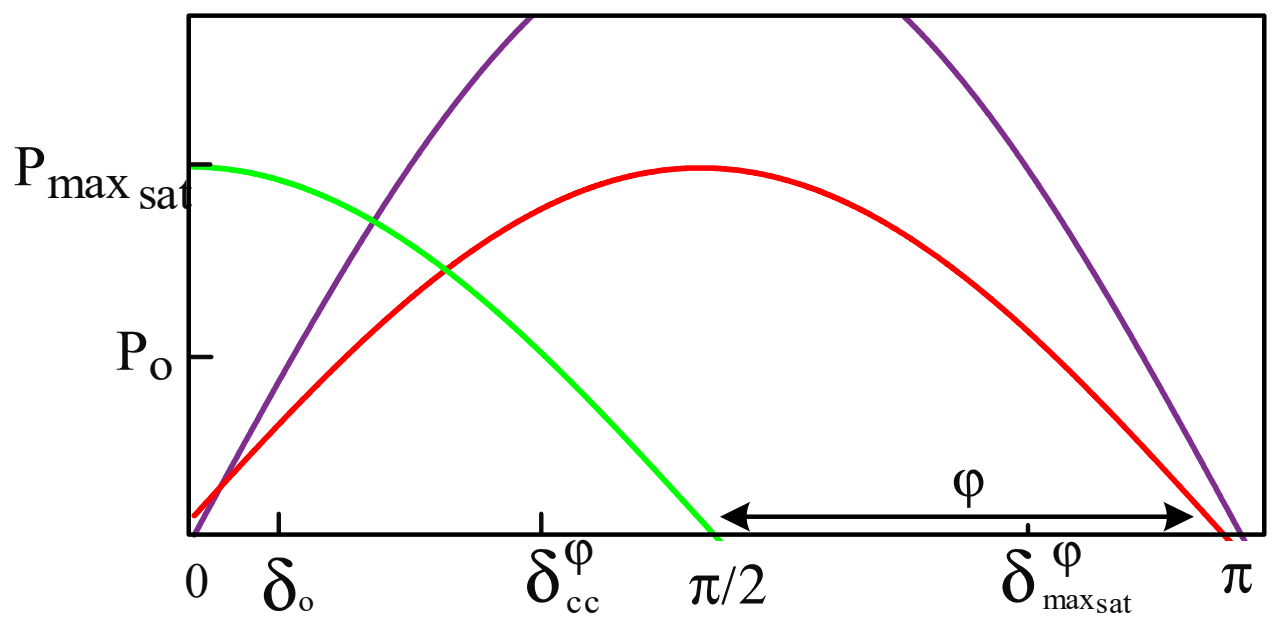

Figure 4. Mechanism of operation of the converter under voltage drop with and without considering the impact of $\varphi[50]$.

In [51], a solution is presented to prevent the converter from overcurrents and instability problems during both symmetrical and asymmetrical faults. In the proposed solution, the control of the converter currents and reproduction of the voltage source behavior are performed through the inner loop, and the outer loop is implemented by a VSM. When each of the three phases extends below the threshold value, the outer loop calculates the magnitude and frequency of the reference voltage and locks them to their pre-fault values. After fault detection, the virtual admittance subsystem is used to limit the converter output reference currents (see Figure 5). $i^{*}$ represents the independent single-phase currents obtained from the comparison of the PCC $\left(\mathrm{V}_{\mathrm{pcc}}\right)$ and the virtual back-EMF voltages of the outer loop. $L_{V}$ and $R_{V}$ are the inductive and resistive components of variable virtual admittance, which are set according to the nominal values $\left(L_{v_{-} n}\right.$ and $\left.R_{v_{-} n}\right)$ in normal performance, respectively, and $I_{m}$ is the maximum current among the three phase currents. 


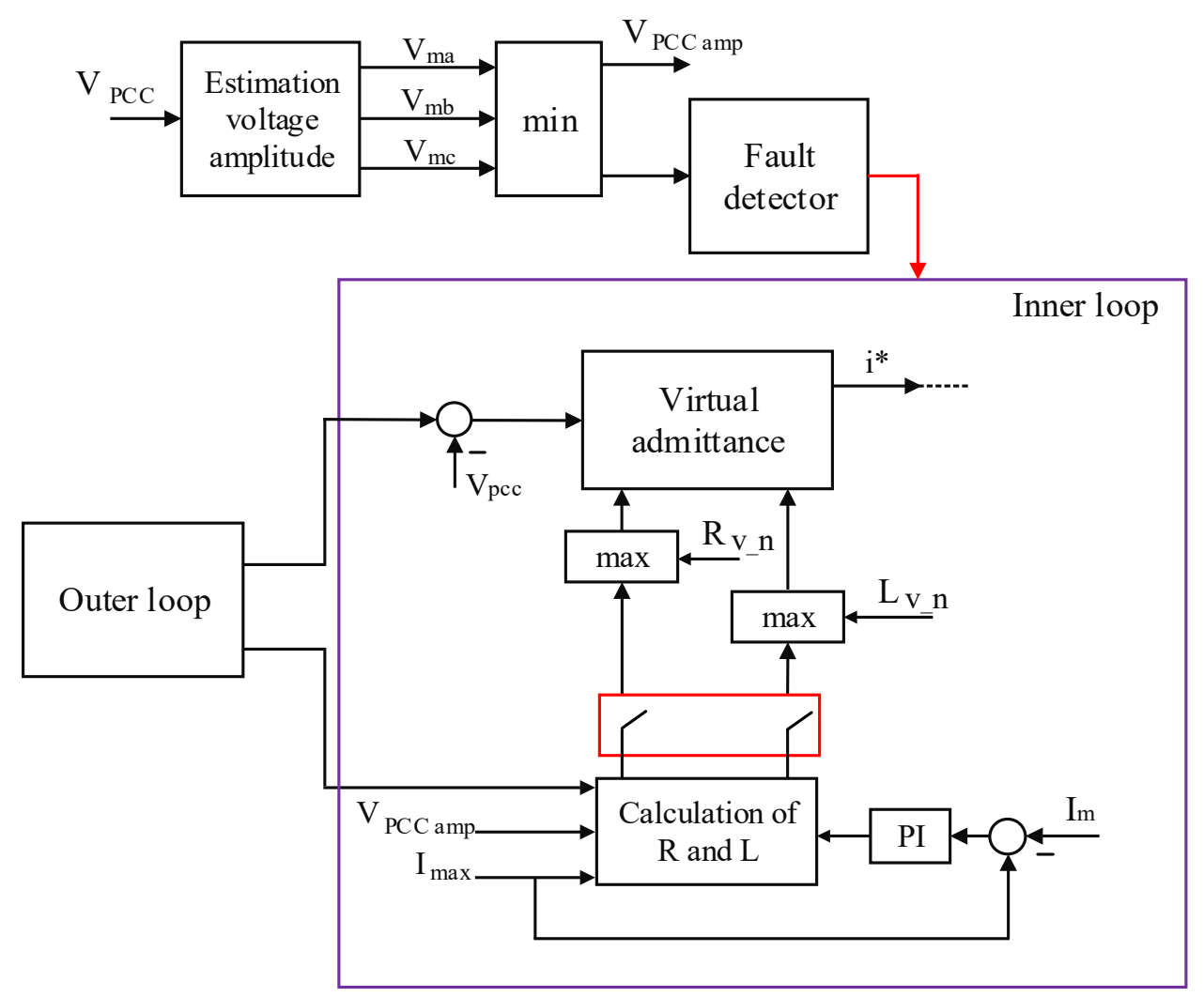

Figure 5. Overview of the proposed control scheme in $\left({ }^{*}\right.$ indicates reference value) [51].

\section{B. Current Limitation along with Post-Fault Improvement}

To limit the current reference in large disturbance conditions of the GFM droop control system, a virtual impedance is used in [52], which limits the current reference by limiting the voltage reference. The dynamic behavior of the system with virtual impedance (VI) and the post-fault synchronization behavior of the system with and without considering the inertial effect and virtual impedance are analyzed. Additionally, in order to improve the post-fault dynamics and transient stability, droop gain is considered variable with respect to the current magnitude and voltage magnitude, the latter of which behaves better in terms of various faults.

In [35], by limiting the current references of the converter with a circular limiter and adjusting the power references when a fault occurs, the outer loops are protected from the instability and wind-up problems. Additionally, a dynamic virtual damping approach to improve the recovery process is presented, which is temporary.

The effect of virtual resistive (VR) in oscillation damping in the process of fault recovery of droop-based GFM converter is investigated in [53] and an adaptive VR (AVR) method is proposed according to the rate of power recovery to solve the problems of fixed-value VR (FVR). Current saturation for overcurrent protection along with the excessive virtual resistance make the recovery process slow or even causes instability, especially in the stiff grid connection. In the proposed model, the value of VR is self-adjusted to sufficiently damp the post-fault oscillation, without any unnecessary resistance in the recovery process. In such a way, if the oscillation is significant, the value of the VR is more than its value when the oscillation is not too intense. The adaptive virtual resistor operation is shown in Figure 6, which is controlled by signals $S_{0}$ and $S_{1}$ and is assigned based on normal or faulty conditions. In this figure, after estimating the intensity of the post-fault oscillations by different filters, e.g., high pass filter (HPF) and low pass filter (LPF), the AVR can be regulated by the $K$. 


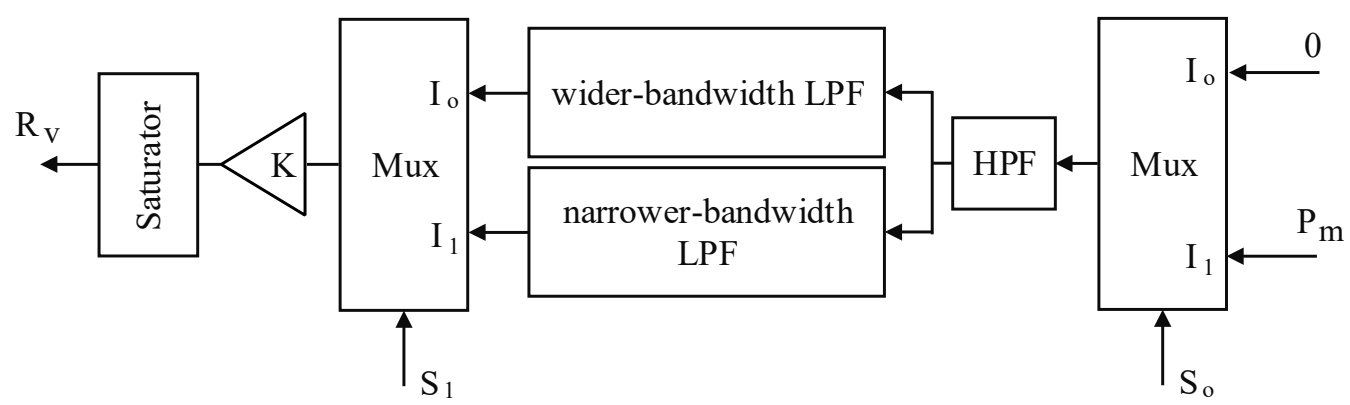

Figure 6. Adaptive virtual resistor operation [53].

\section{Without Overcurrent Stimulation}

In [54], a mode-adaptive power angle control scheme is proposed to improve the transient stability of VSG. In this scheme, in a large disturbance, after detecting the feedback mode of the power angle control loop, the loop gain changes from the positive to the negative feedback mode (see Figure 7), where $\mathrm{H}$ and $\mathrm{D}$ are the inertia constant and damping coefficient, respectively. $P_{\text {ref }}$ is the active power reference and $P_{o}$ is the output active power of the VSG. Therefore, the problem related to the loss of synchronization can be clear in the situation of the system having equilibrium points after disturbance. While a limited dynamic response of the power angle $\delta$ can be achieved with the mode adaptive control in the severe grid faults without equilibrium points, the VSG can achieve stability even when the fault clearing time (FCT) is higher than the critical clearing time (CCT). In this study, a variable $\mathrm{k}$ is changed in order to switch between the negative feedback mode $(\mathrm{k}=1)$ and the positive feedback mode $(\mathrm{k}=-1)$.

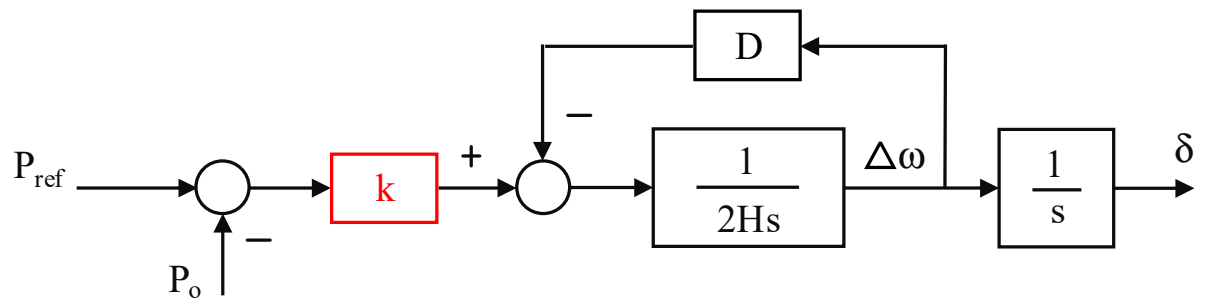

Figure 7. Control diagram of the active power loop with the mode adaptive control scheme [54].

In [56], in order to improve the transient stability of the system, a transient damping method is used, which is implemented according to the frequency deviation with the VSG frequency through a HPF and combination with the active power control loop. Figure 8 shows the proposed control block diagram in which $\mathrm{J}$ and $\mathrm{D}$ are the virtual inertia and droop gain, respectively. Additionally, the optimal controller parameter is determined to enhance the transient stability.

The transient angle stability of the VSG-based grid connected system is proposed in [55]. In this paper, the stability of the torque-form and power-form emulation of VSG methods is discussed and the former shows better stability than the latter in low-inertia conditions. Then, the effect of the internal voltage on transient angle stability is analyzed and a control method is proposed, which improves the large-signal angle stability with decreasing the acceleration and increasing the deceleration zones by proper control of internal voltage (see Figure 9). In Figure 9, $\mathrm{U}_{\text {ref }}$ and $\theta$ are the voltage and angle of the internal voltage generated by the VSG active and reactive power loops, respectively; the output active power and frequency (reactive power and voltage) are shown by $\mathrm{P}(\mathrm{Q})$ and $\omega$ $(V)$, respectively; $P_{o}\left(Q_{0}\right)$ and $\omega_{o}\left(V_{o}\right)$ are the setpoints of the active power and frequency (reactive power and voltage), respectively; and $\mathrm{K}$ is the control gain. 


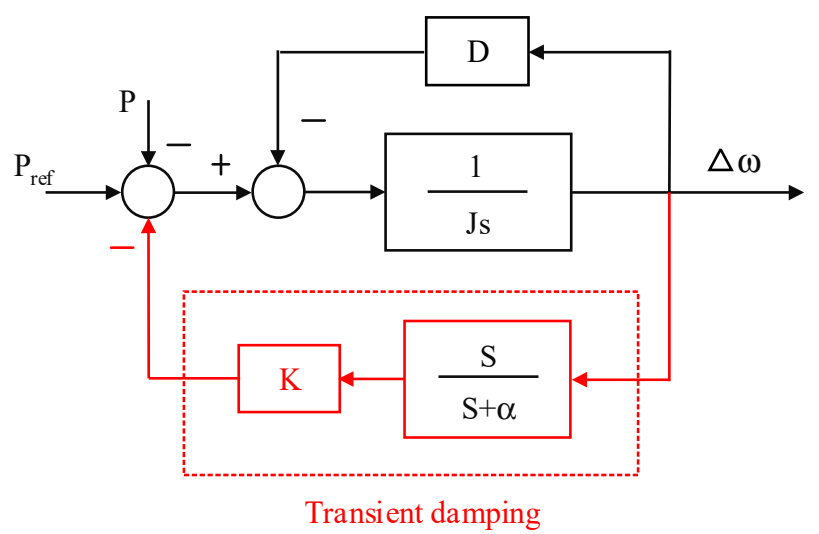

Figure 8. Block diagram of the transient damping control [56].

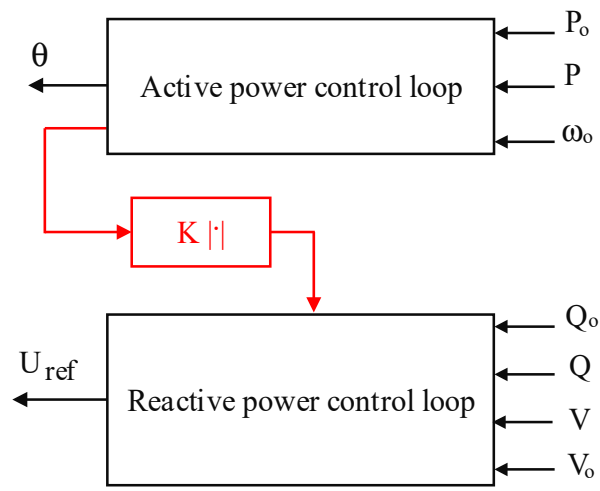

Figure 9. Control diagram of the enhanced large signal angle stability control method of VSG [55].

\subsubsection{Small-Signal Stability}

The small-signal stability of the converter is its ability to return to its initial operation without oscillation under small disturbances. Due to the difficulty of regulating the point of the common coupling voltage in strong grids for GFM converters, this can cause oscillations and small-signal instability in the system [57]. However, in weak grids, these converters have robust small-signal stability, therefore, due to their voltage regulation capability, the use of GFM converters can improve the grid strength and are widely used in weak grids integration to eliminate the small-signal instability [58,59].

Several studies have been published to analyze the small-signal stability in GFM converters. In [60], the robust stability of a grid connected synchronverter is analyzed by considering the influence of the variation of control parameters and grid conditions on system stability through structured singular values (SSV) or $\mu$-analysis as a suitable tool for analyzing control robustness. According to this study, the robust stability of the synchronverter is improved in weak grid conditions. The authors of [61] reveal that the stability of the system in weak-grid conditions can be enhanced by use of a GFM controller. In this study, the stability of the VSM-based system is investigated under various parameters, including the grid impedance, the VSM parameters and the virtual impedance (VI) using the system eigenvalues and singular values. A new scheme for designing the VSM parameters along with VI is proposed to enhance the stability margins of the system at different grid impedances.

In [62], an intelligent power oscillation damper (iPOD) consisting of a band-pass filter and two proportional gains is added to the VSG control with the aim of damping the electromechanical power oscillation. In this research, after predicting the oscillatory frequency, which is set as the frequency of the band-pass filter, the gain of the active power control loop at this frequency increases and, with the damping of the oscillations, the stability of the system also increases. 


\subsection{Resonance Stability and Converter-Driven Stability}

The resonance stability is incorporated with mainly subsynchronous resonance (SSR) associated either to electromechanical (torsional) or purely electrical resonance. The SSR can be formed into two ways: resonance between series compensating network elements and mechanical torsional frequencies of the conventional synchronous generator shat; and resonance series compensating network elements and the electrical characteristics of the generator. In the case of the electrical resonance, it is occurred due to the effective reactance (self-excitation effect) of the DFIG (Double Feed Induction Generator) windturbine generators, which creates electrical resonance with the series compensation network elements [63].

In regard to the converter-driven stability, it is associated with the power electronic converter controls. The slow- and fast-interaction timescale controls of the converter-based generators may create cross couplings with the electromechanical dynamics of machines and the electromagnetic transients of the network. As a result, a wide range of low-tohigh frequency oscillations $(0.5 \mathrm{~Hz}$ to several $\mathrm{kHz})$ can be observed. For example, the interactions of the fast inner-current loops of the converter-based generators with passive network components may cause several kilohertz high frequency oscillations [64]. It is reported in [65] that the VSG in a low-inertia grid may initiate super-synchronous stability issues due to converter control interactions. Therefore, a properly tuned VSG controller will reduce these types of fast oscillations [66]. However, it will require more investigation on how to optimize the VSG controller in different network conditions.

The impedance interaction between a VSG and series compensated grid can lead to a low-frequency oscillation problem, particularly in the weak grid connected system. Under these conditions, coupling the VSG impedance with the series compensated network can cause low frequency subsynchronous resonance ranges between $0.5 \mathrm{~Hz}$ and $50 / 60 \mathrm{~Hz}$, since this resonance can lead to further power losses as well as system instability. In [67], to mitigate the low frequency subsynchronous resonance problem of this system, an impedance reshaping control scheme based on adding a current feedforward control to the modulation voltage is proposed (see Figure 10). In [68], for the grid-interactive dynamic analysis of the droop-control-based converter an $\alpha \beta$-frame complex-value-based output impedance model with the simplified single input-single output impedance-based stability study is proposed. This study, based on frequency analysis, indicates that the low frequency oscillations become more intense under stringent grid conditions, due to the interaction between the inner voltage, current controls and the outer power control loop. In [69], to damp the low frequency oscillations, a multirotor virtual machine controller is proposed. By using multiple virtual rotors, the converter has higher freedom to control the low frequency oscillations. In this method, the desired oscillation frequencies are set using the decoupling network block and then the desired attenuation at these frequencies are performed through the virtual rotors.

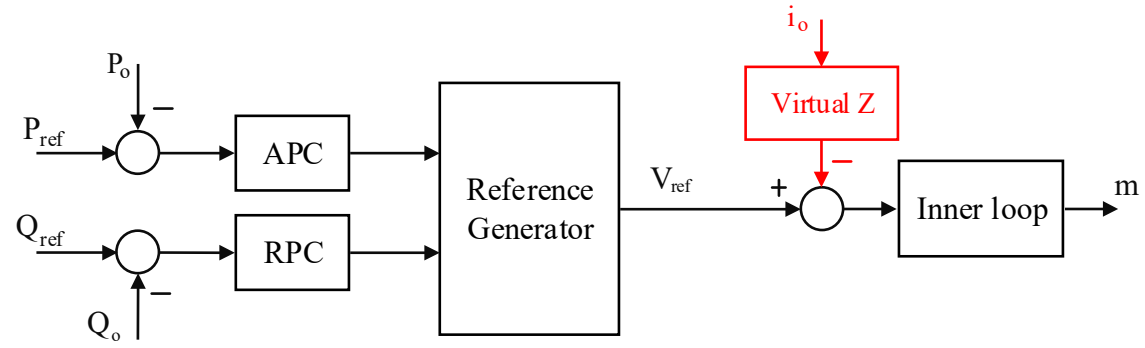

Figure 10. Proposed control scheme in [67].

The study in [70] analyzes the stability of a VSG-based grid connected system by considering the effect of VSG inner control loops. This study shows the significant effect of inner loops on VSG output impedance and its adverse effects on the system stability. Considering the inability of inner loops to damp the oscillation that enters into the system, a virtual resistor with an appropriate value is used to dampen this oscillation (see Figure 11). 


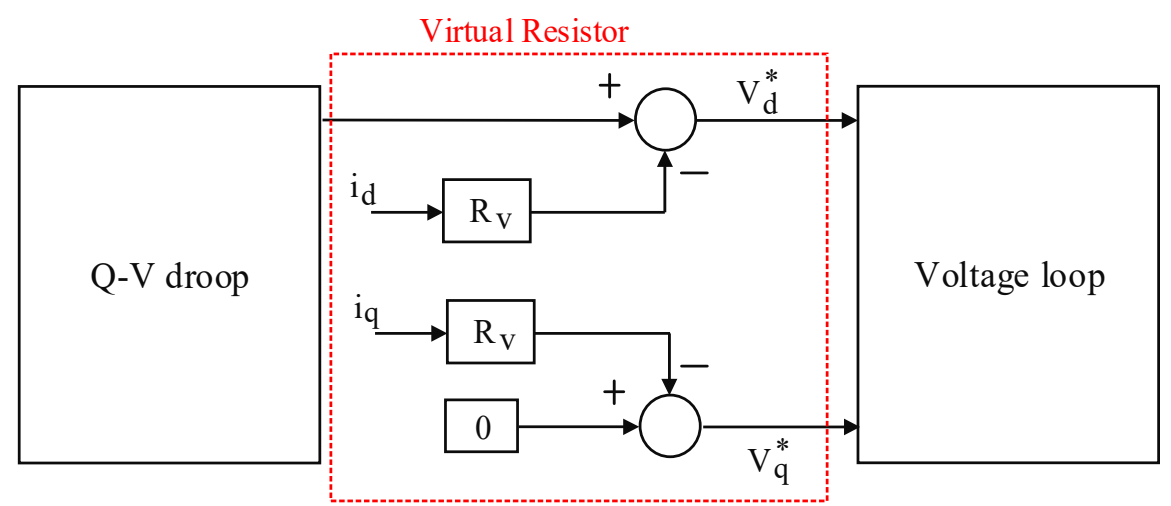

Figure 11. Control scheme of VSG along with a virtual resistor (* indicates reference value) [70].

In [71], after analyzing the effect of line parameters and control parameters on dynamic power angle oscillations, a new virtual impedance damping scheme is proposed. The aim of this scheme is damping the oscillations in the low frequency range of the droop-controlledbased grid connected system by overcoming the weakness affecting the system steady-state operation that exists in the traditional scheme.

\subsection{Frequency Stability}

In modern power systems by extensively utilizing renewable energy resources, grid connected converters are responsible for frequency regulation and suitable control structures play an important role in achieving this. In some situations where the required energy is not supplied, implementing energy storage is a reliable solution. GFM converters have some new options in terms of frequency regulation, as they can regulate power without any delays. Similar frequency dynamic response to synchronous generators can be achieved through implementing VSG control. To overcome the VSG frequency oscillation, in [72], the influences of the controller parameters variation on the power and frequency are studied, and its operation is improved by adaptively changing the controller parameters. In [73], the voltage and frequency stability of the VSG-based grid connected system under weak grid conditions is analyzed. For frequency oscillation analysis, the motion equation is proposed and the study shows that there is a direct correlation between the grid stiffness and synchronization capability, whose stronger stiffness is better for VSG synchronization with the grid during the disturbance.

\subsection{Voltage Stability}

In [14], the voltage stability of a power system under small disturbances is compared using GFM and GFL controls. In this study, employing GFL control causes instability in the system, while their replacement with GFM control strategy by actively suppressing a disturbance shows stable performance. To measure voltage stability, in [73], which analyzes the voltage and frequency stability of a VSG-based grid connected system under weak grid conditions, impedance-based modeling for VSG in a synchronous inertial reference coordinate (SIRC) is proposed.

\section{Control Method for Harmonic Mitigation}

Because of the different fundamentally terminal characteristics that the two types of grid-connected inverters have, each of them creates specific implications in the power system and also have different challenges and levels of difficulty to achieve their specific stability and power quality targets [74]. In the grid-following mode, to have enough high control bandwidth, the current compensator is designed and harmonic current rejection in corresponding frequencies is provided by high gain control at the harmonic frequencies [75]. Explicit active damping is needed to make the current controller stabilize against harmonic resonance instabilities of interacting between the higher order filter (LC/LCL), the grid and the controller of implementing delay [76-78]. 
In GFM converters, without the need to explicitly regulate the output current, it is necessary to respond to the conditions of the grid using the voltage and frequency of the converter terminal and adjust the active and reactive output power around the set points. These converters typically use control methods, including primary control loops, such as droop control or VSM control. Without harmonic mitigation, in the grid-following mode, all harmonics are automatically pushed to the grid side and make the PCC polluted, whereas in the other mode the harmonic currents can be shared with the grid side based on their respective impedances. Therefore, without the harmonic mitigation control scheme, the grid-forming mode leads to less voltage harmonic distortion in the PCC [79].

With the increase in the use of nonlinear loads, the problems related to the grid power quality increased. These loads add distortion to the grid current and cause distortion in the grid voltage. Another problem that the grid faces is the reduction in the power factor, which is the result of the drawing power by large inductive loads and imbalance in the three phase distribution grid can cause a neutral current to follow through the neutral conductor $[80,81]$. An integration of power electronic-based renewable energy with the grid increases harmonic distortions in the system. In order to solve the aforementioned problems, different control methods are used in the literature. According to the review results in this paper, a classification of the existing control methods to improve the power quality is shown in Figure 12.

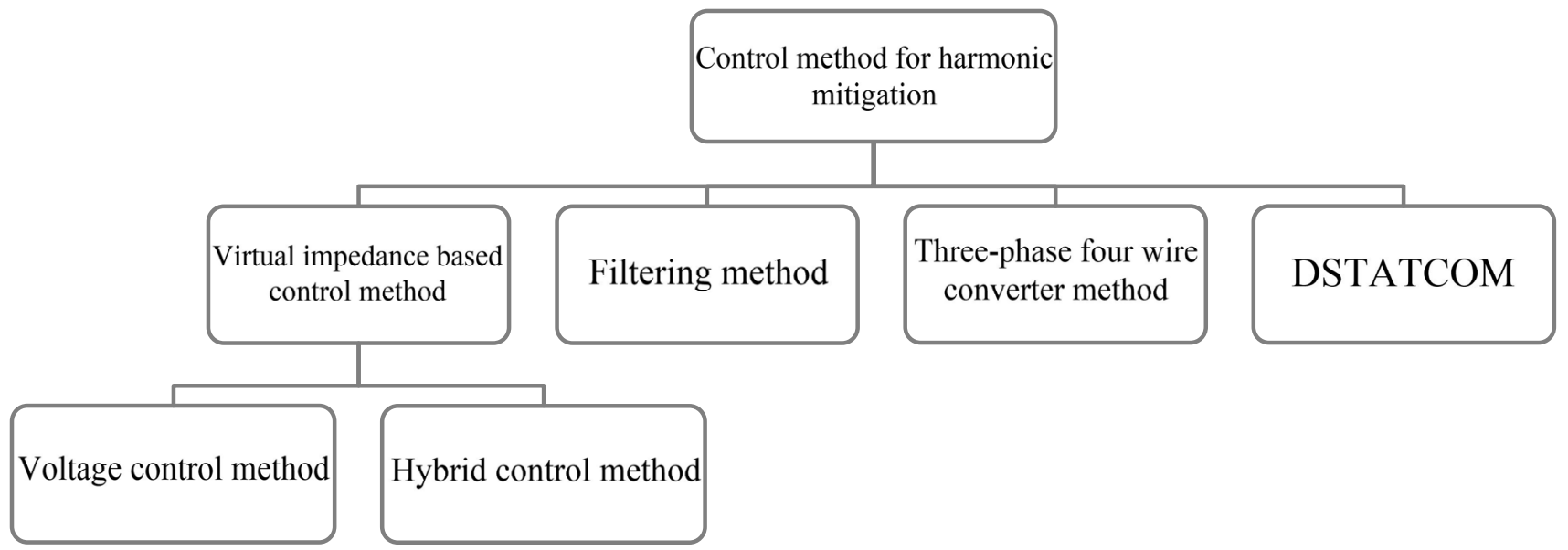

Figure 12. Classification of the existing control schemes for harmonic mitigation.

\subsection{Virtual Impedance-Based Control Scheme}

Virtual impedances can be used in converter control for applications, such as harmonic voltage compensation and increased stability, and also can be used with the aim of keeping the voltage within certain limits, having sufficient reactive power sharing, providing system damping and decoupling the active and reactive power [82].

Traditionally, by using virtual impedance methods, harmonic current sharing can be achieved [83-87], which can behave as a physical impedance without its real presence in a system and make the line impedance effective by considering a virtual harmonic resistance at the inverter output [88]. The authors of $[84,89,90]$ show the increase in the line impedance by using the positive harmonic resistance technique, which reduces the quality of voltage. However, by developing the negative virtual impedance concept in [85], the harmonic sharing is achieved without influencing the voltage quality. Virtual impedance can be a resistor, an inductor or a combination of both of them [82]. Based on being at the fundamental or harmonic frequencies, virtual impedance can control the power flow and grid disturbance ride through or active damping and harmonic mitigation, respectively [79].

In this section, various control schemes based on virtual impedance are discussed. 


\subsubsection{Current Control Method (CCM)}

Harmonic compensation in grid-connected renewable energy sources can be realized by using the CCM [91-93]. In this control method, the current line is controlled based on the modified current reference, which is modified according to the harmonic compensation requirement and the inverter available power rating [79]. To achieve the purpose of PCC voltage harmonic mitigation, the converter side is controlled to operate as a small damping resistor at the selected harmonic frequencies. Therefore, more harmonic currents of nonlinear loads are absorbed by the converter side and the grid mainly provides sinusoidal fundamental current. As a result, the harmonic distortion of the PCC voltage is improved [91,94].

\subsubsection{Voltage Control Method (VCM)}

The VCM-based control method can be used in both grid-connected and islanded modes. By using a virtual harmonic impedance control, the VCM can obtain a reliable PCC harmonic mitigation. In order to track the voltage reference, a double loop voltage controller is generally incorporated, with the PR controller in the outer loop, to control the voltage of the filter capacitor. By adding a feed-forward term of a harmonic voltage reference, the voltage reference is modified [95].

The VCM and hybrid control method (HCM), which can be innovative control methods, are used as grid-forming converters for harmonic mitigation.

\subsubsection{Hybrid Control Method (HCM)}

Due to the limitations of conventional CCM and VCM, the HCM has been presented in the literature.

Using dead time between the switches of the leg of the inverter will cause output voltage harmonics in a low frequency range. As the impedance of the grid is low at a low frequency, the small output voltage harmonics can cause a serious distortion of the injected grid current. In [96], to improve the injected grid current quality, a virtual series impedance in order to increase the output impedance is used. Additionally, to not affect the dynamic performance, this virtual impedance is designed to be high just at harmonic frequencies of the injected grid current. As shown in Figure 13, an output voltage closed-loop is used to suppress the voltage harmonics. The output active and reactive power (Pout and Qout) are calculated via the output voltage $V_{c}$ and the injected grid current ig. With the sensor gain of $\mathrm{H}_{\mathrm{V}}, \mathrm{V}_{\mathrm{c}}$ is fed back and compared with $\mathrm{V}_{\text {ref }}$, then the error is sent to the voltage regulator $\mathrm{G}_{\mathrm{V}}(\mathrm{s})$. In addition, to dampen the output filter resonance, the capacitor current $\mathrm{i}_{\mathrm{C}}$ is fed back with the sensor gain Hi. The system contains two computation delays and PWM delay. The former is the time period between the sampling instant and the PWM reference update instant for sampling and calculation and is modeled as $\mathrm{e}^{-\mathrm{sTs}}$, and the latter is due to the effect of the zero-order hold $(\mathrm{ZOH})$ and maintaining the PWM reference constant after its update.

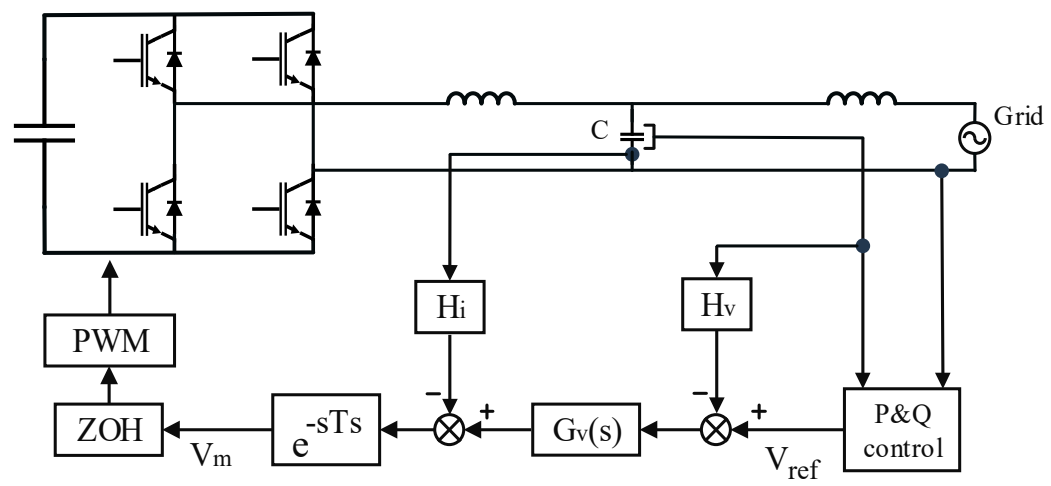

Figure 13. Structure of the voltage-controlled grid-connected converter [96]. 
With reducing the inertia of the power system in grid-connected renewable energy sources, which affects the frequency and voltage and even causes system instability, the virtual synchronous generator (VSG) control method to solve the inertia shortage and frequency fluctuation is proposed [97-99]. This method, by imitating the primary power regulation and primary frequency regulating behavior of the synchronous generator, creates inertial support for the grid. Since most of the renewable energy sources are located in remote areas, they are weakly connected to the grid. Therefore, using the VSG method, an oscillation or interaction between VSG and the grid is created and the power quality of VSG is affected by the distorted grid voltage. Thus, to mitigate the current harmonics, the harmonic impedance of the converter can be reshaped [100,101].

As suppressing various types of harmonics (such as subsynchronous harmonics and non-integer high frequency harmonics) are difficult by one conventional solution in a VSG-based grid connected system, Ref. [101] proposes a magnitude-reshaping strategy to increase output impedance in all harmonic frequency bands. This strategy comprises a notch filter and harmonic regulator, in which the former extracts harmonic components of the grid current and the latter increases the equivalent harmonic impedance. According to Figure 14, the feedback variables, $i_{\text {gabc }}$, reshape the output impedance of VSG. Using the notch filter $G_{N}(s)$, the harmonic component $i_{\text {oabc }}, i_{h}$ is extracted. Then, the output impedance of the inverter in the harmonic frequency domain is improved with the harmonic regulator $\mathrm{G}_{\mathrm{PD}}(\mathrm{s})$ and the harmonic voltage reference $\mathrm{m}_{\mathrm{h}}$ is generated. The equivalent circuit of the magnitude-reshaping strategy for VSG-based grid-connected system under different loads is shown in Figure 15. The authors of [98,102] analyze the dynamic performance of VSG and ignore the coupling impedance degree as a result of the reshaping effect of VSG impedance, while in [101], to analyze the effect of impedance reshaping on VSG, a frequency coupling impedance model is considered, and the frequency response of the coupling impedance compared to the other mentioned methods in this paper shows that the proposed method has the least impact on the grid-connected stability assessment.

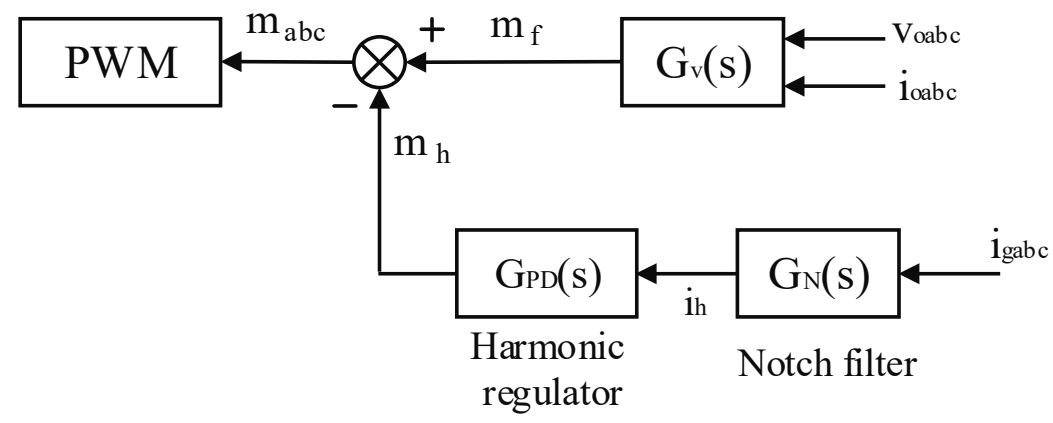

Figure 14. Topology of the proposed reshaping strategy [101].

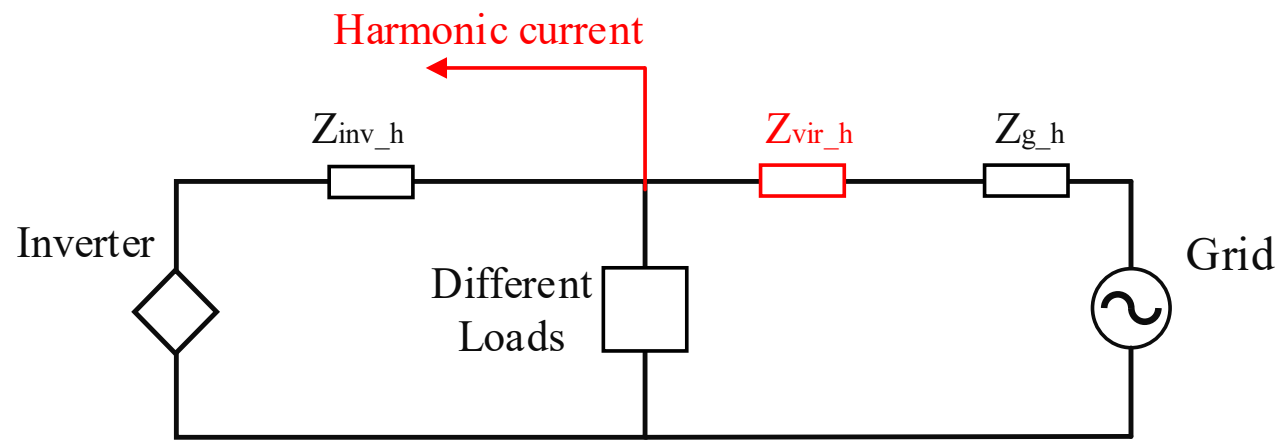

Figure 15. Equivalent circuit of magnitude-reshaping strategy for the VSG-based grid-connected system under different loads [101].

Due to the fundamental limitation of VSG harmonic inhibition in the presence of a distorted grid and nonlinear loads, a unified harmonic control structure is presented 
in [103] with a tunable tradeoff between the two constrained harmonic sources. In order to extract the harmonic components, a multiple harmonic sequence components observer (MHSCO) is presented instead of low pass filter (LPF), which facilitates the dynamics and accuracy of the multi-order harmonic estimation. In this paper, to improve the local voltage and grid current quality, the equivalent output impedance and grid admittance are regulated, respectively. Therefore, a complete suppression of the two distortion sources is conducted through a hybrid harmonic suppression strategy with a local voltage feedback control and adaptive grid current compensation, which reduces the harmonics and gains a high quality power supply for VSG. Based on Figure 16, the VSG harmonic voltage reference is expressed as:

$$
u_{V S G}^{h}=G_{r}^{h}(s)\left[\alpha\left(0-i_{g}^{h}\right)+\beta\left(u_{0}^{h}-0\right)\right]
$$

where $G^{h}{ }_{r}(s)$ is a PI controller; $\alpha$ and $\beta$ are adjustable parameters; and $u_{V S G}^{h}$ is tracked by a dual loop with $G^{h}{ }_{u}(s)$ and $G^{h}{ }_{i}(s)$ as a PI and P controller, respectively. $u_{V S G}\left(u_{o}\right)$ is the inverter voltage (output voltage) and $i_{i}\left(i_{o}\right)$ is its (output) current. $u_{g}$ is the grid voltage and $i_{g}$ is its current.

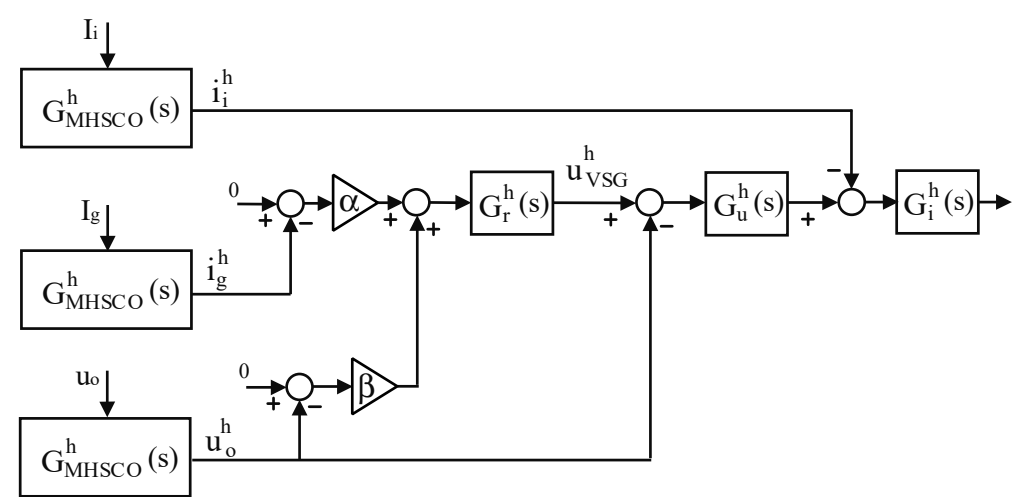

Figure 16. Scheme of the unified harmonic mitigation with a tunable tradeoff [103].

In a stable state of the system, the above equation is obtained as follows:

$$
G_{r}^{h}(s)\left[\alpha\left(0-i_{g}^{h}\right)+\beta\left(u_{0}^{h}-0\right)\right]=0
$$

Based on Equation (4), a tradeoff can be achieved between the power quality of the local voltage and the grid current. For this purpose, three cases $((\alpha=0, \beta \neq 0),(\alpha \neq 0$, $\beta=0)$, and $(\alpha \neq 0, \beta \neq 0)$ ) can be considered to make a tradeoff between voltage and current distortions.

By using MHSCO, as shown in Figure 17, the harmonic components $\mathrm{u}_{\mathrm{o}}{ }^{\mathrm{h}}$ and $\mathrm{i}_{\mathrm{i}}{ }^{\mathrm{h}}$ are extracted and the sum of the fundamental voltage reference and harmonic voltage reference, which are generated by the conventional VSG control and harmonic voltage control loop, are sent to the cascade voltage and current control. Then, the harmonic voltage drop across the output impedance of the inverter can be compensated. In addition, to deal with the adverse effects of a distorted grid, an adaptive grid current-controlled compensator is designed. In the proposed method, the output impedance of the VSG, $Z_{0}$, in the h-th harmonic is greatly reduced compared to the original value. As a result, a smaller drop occurs on the output impedance, and because of the reduced equivalent output impedance, most of the load harmonic current $i_{1}{ }^{h}$ is absorbed by the VSG side and the quality of the local voltage is improved. Additionally, by using the adaptive current-controlled voltage compensator, the amplitude of admittances in the desired harmonic frequencies are reduced, therefore the harmonic current caused by the distortion grid voltage $u_{g}{ }^{h}$ is effectively mitigated. 


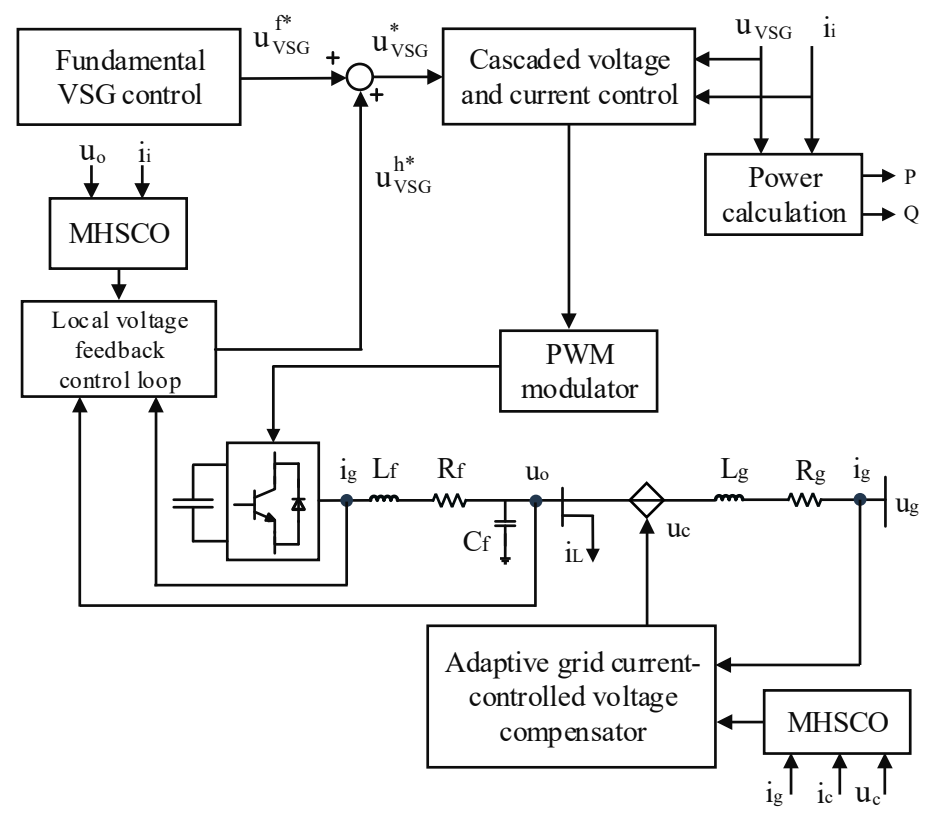

Figure 17. Control scheme structure proposed in (* indicates reference value) [103].

In VSG, the magnitude of inrush fault current is affected by the voltage-controlled harmonic suppression method in the grid symmetrical fault situation, because of the inverse effect of the output impedance on the grid harmonic current and inrush fault current. Figure 18a shows the structure of the system topology, where VSG is located at the PCC with nonlinear load and the grid short-circuit fault occurs between the grid side and PCC, and in Figure 18b, an equivalent circuit of VSG connected to the grid is shown. Based on this figure, it can be seen that there is a direct relationship between $\mathrm{i}_{\text {gh }} / \mathrm{i}_{\text {loadh }}$ and $Z_{\text {out }}$. Therefore, the smaller $Z_{\text {out }}$ is, the smaller $i_{\text {gh }} / i_{\text {loadh }}$ is, and the effect of nonlinear load current on the power quality of grid current is reduced. In this situation, in order to reduce the grid harmonic current, the output impedance must be reduced, while this reduction increases the transient inrush fault current and its steady-state operation in the grid symmetrical fault condition. In [104], to solve this problem, two virtual impedances are added to the circuit. One impedance is added in parallel with the output impedance, which can contribute to the suppression of the grid harmonic current by reducing the output impedance. Additionally, the other one is located between the point of grid fault (PGF) and PCC in order to restrict the inrush fault current (see Figure 19), while most previous researches have focused on output current peak limitation techniques for the current-controlled or direct power-controlled inverters that adjust the active and reactive power control coefficients and keep the injected current at a safety value, which is difficult to use in open loop voltage-controlled VSG as it has no inner current loop.

Since the virtual impedance (VI) cannot solve the problems that exist in the Virtual Synchronous Generator (VSG) under a non-ideal grid, a configurable virtual impedance (CVI) is presented in [105]. By using this method, the system is capable to decouple the control of active and reactive power and also mitigate the harmonics caused by the nonideal grid. In this method, the power decoupling is used through virtual fundamental positive sequence impedance, while the other virtual impedance sequence is used to suppress the current distortion. Additionally, a novel harmonic extraction algorithm (NHEA) based on state space model is presented in order to extract the positive-sequence, negative-sequence and zero-sequence components from the output current. According to the NHEA, 90-degree-phase lead for sequence components can be achieved through a simple vector rotation; then, by adjusting the virtual impedance for each of them, VSG can have both the power decoupling and output current quality control. 


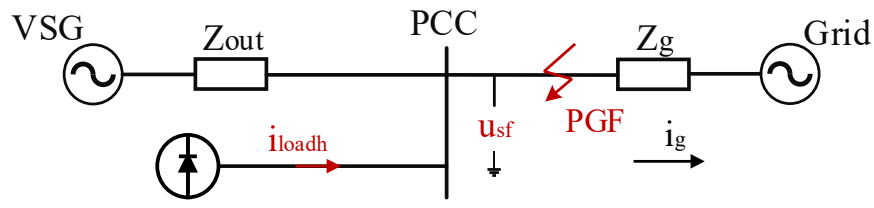

Nonlinear load

(a)

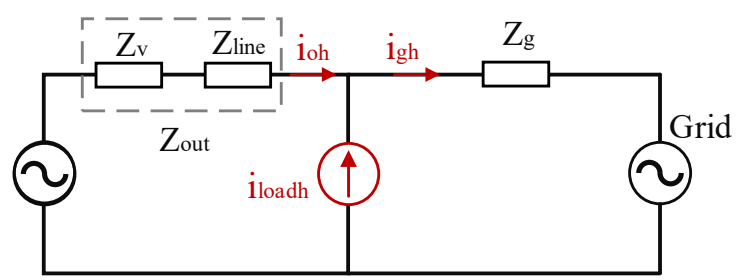

(b)

Figure 18. (a) Structure of the system topology; (b) Equivalent circuit of VSG connected to the grid [104].

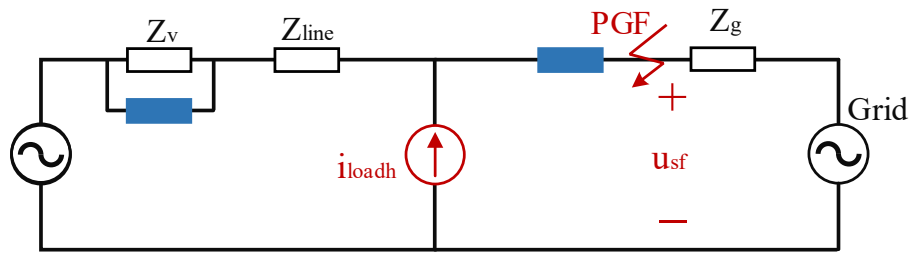

Figure 19. Mitigation scheme of the harmonic current and the transient inrush fault current [104].

\subsection{Filtering Method}

Notch filter is a linear filter that works by multiplying a unit gain in all frequencies, except notch frequency, in which its gain is zero. However, if the frequency changes with the time, this filter cannot work properly. Therefore, an adaptive notch filter is proposed, which can change the notch frequency based on tracking the input signal $[106,107]$.

Some adaptive notch filter multifunction control methods for the grid-connected system and their comparison with the integer order notch filter design are presented in [108-110]. The notch filter is usually used to reject unwanted frequencies from the signal and to choose other frequencies that one wants by regulating high gains at the same frequency [111]. The drawbacks of integer order notch filter and other filters are related to their fixed integrator or differentiator term [112]. To tackle these fixed structure limitations of an integer order filter, fractional order filters are presented in [113]. Unlike the integer order notch filters, the fractional order filters are capable of producing different gain terms between $0 \mathrm{db}$ /decade and $\pm 20 / 40 \mathrm{db}$ and make the power of the integrator more flexible, which can be tuned to obtain a desirable and precise response during the operation as well as having the capability of gaining an asymmetrical gain response curve.

This method is used more in the field of signal processing [114,115]. In the field of power electronics control, in [116], a developed Fractional Order Notch Filter (FNOF) is proposed to control a grid connected PV system, which can solve power quality problems, such as the existence of harmonic current on the grid side, reactive power demand from the load and unbalanced load currents. The transfer function of FNOF is expressed as:

$$
G_{F O N F}=\frac{\xi \omega s^{\beta}}{s^{\alpha+\beta}+\xi \omega s^{\beta}+\omega^{2}}
$$

where $\xi$ is damping factor, $\omega$ is the natural frequency, and $\alpha$ and $\beta$ are fractional parameters, which are variable in the interval $(0,2)$. By considering $\alpha=\beta=1$, Equation (5) becomes a conventional second order notch filter. This control method is used to obtain fundamental 
current components of distorted load currents and generate gate pulses of voltage source converter of the system to provide the required load active power from the PV and mitigate the grid current harmonics distortion and compensating reactive power and load unbalancing. In [117], to improve the power quality of three phase grid connected PV system under different conditions (voltage distortion and voltage unbalance), a new multiple improved notch filter (MINF) control algorithm is proposed. This control algorithm improves the power quality of the system by reducing the harmonic components (capable of rejecting higher order harmonics) of load currents independent of the voltage signal, which plays an important role in the good performance in different grid voltage conditions (voltage distortion and voltage unbalance) and, by compensating the required reactive power of the nonlinear load, improving the power factor. In order to determine the maximum power point tracking (MPPT), the $\mathrm{P} \& \mathrm{O}$ algorithm is used in this paper.

\subsection{Three-Phase Four Wire Converter Method}

An adaptive learning based back propagation (AL-BP) control technique is used in [118] to improve the power quality of a three-phase four-wire grid interactive PV-battery system. In this scheme, by using the AL-BP algorithm, the fundamental real and imaginary power components of load currents in all phases are extracted, and a boost converter and a bidirectional DC-DC converter are used for MPPT and charging the battery, respectively. This study was conducted through nonlinear and unbalanced loads when a load on one phase is disconnected. The fourth leg of the converter supplies the harmonic currents of the load and compensates reactive power to keep the system voltage constant at PCC. Therefore, there is no need for a grid to supply harmonic current. So, the power quality is improved under unbalanced loading conditions. In this situation, there are different shapes of currents in each of the three phases of the converter to have balance currents and power in the grid side.

\subsection{DSTATCOM}

To improve some of the problems related to grid-connected VSC systems, such as reactive power compensation, harmonics mitigation and load unbalancing, a distribution static compensator (DSTATCOM) is used in some industries [119]. The salient problem of this method is its high implementation cost. In order to find a solution based on learning and tracking capability, the distributed sparse (DS) control method is used in different fields. In [120], to solve the problem of optimal use of sparsity in the conventional LMS (Least Mean Fourth) method, a LMF (Least Mean Fourth) filter is introduced that is able to partially eliminate this problem, but its operation is affected by noise and input. This drawback is solved by introducing a distributed based adaptive filter in [121,122]. To solve the drawbacks of the conventional LMF method and improve the steady-state behavior, an adaptive sparse method is presented in [121,122]. In [123], a novel multipurpose DS (Distributed Sparse) control approach is proposed for the grid-connected PV system, which can operate in different solar radiations and mitigate the harmonics of the loads and create a balanced grid current. In the absence of access to solar radiation, the system operates as a DSTATCOM using the same voltage source converter, which is cost effective.

\section{Conclusions}

The application of GFM converters is a promising solution to the problems of the high penetration of converter-interfaced renewable resources integrated into low-inertia grids. This paper explores various challenges related to GFM converters, including frequency deviations, black start capability, angle stability, frequency stability, voltage stability and harmonic mitigation. Moreover, various control schemes presented in the current literature are reviewed. In terms of frequency deviation, the consequences of not limiting the RoCoF in low-inertia systems are discussed and several methods to limit frequency deviation and increase the inertia of the power system, including synthetic inertia and utilizing energy storage system, are summarized. The concept and phenomena of the power system stability 
in modern power systems and stabilization strategies with respect to different stability classes, including angle stability, frequency stability and voltage stability, are discussed and we pointed out that the GFM converters are preferable to GFL converters, especially in low-inertia systems. Under large grid disturbances with respect to the low current rate of switches in GFM converters, different control methods to limit the overcurrent are explored. Additionally, regarding the voltage regulation capability of these converters, several studies have analyzed their robust small signal stability in weak grid conditions. In order to suppress various types of harmonics, different control techniques, including virtual impedance-based method, filtering method, four-wire converter method and DSTATCOM, are discussed.

\section{Future Scope}

While the GFM converter is an exciting new technology for grid integration of renewable energy resources, there are a few challenges that are yet to be addressed for the effective operation of the renewable rich power grid. This technology is not a "silver bullet" that can solve all challenges in the power system. The thoughtful implementation of this technology alongside other technologies and techniques needs to be critically studied for managing the transition to renewables. The assessment of the cost-benefit analysis is also important to evaluate the implementation of the GFM converters with other technologies, such as synchronous condensers and GFL inverters. Although the GFM converter helps the nearby GFL converter to operate stably, it is itself susceptible to small signal instability due to the faster inner control loops. In-depth studies are required to investigate the use of the power system stabilizer (PSS) in the control facilities of the GFM converters, which has been historically used in synchronous generators to manage small signal stability. The construction of the exact definition of the new GFM converter technology is complex, as its characteristics are quite similar to the synchronous generators. To date, the grid codes for the GFM converters integration into the grid are not mature, for example, the system operators/regulators are still not fully clear whether this technology can be part of an asynchronous or synchronous generator type for assessing its performance. Therefore, the grid codes need to be thoroughly studied to facilitate the GFM converter technology implementation. Finally, a detailed study is required to formulate the exact required number of GFM converters to replace the existing GFL converters to ensure a secure system operation with minimum cost.

Author Contributions: Conceptualization, E.B., M.R.I. and M.M.R.; methodology, E.B., M.R.I. and M.M.R.; software, E.B.; validation, M.R.I. and M.M.R.; investigation, E.B. and M.R.I.; data curation, E.B. and M.M.R.; writing—original draft preparation, E.B.; writing—review and editing, M.R.I, M.M.R. and K.M.M.; supervision, M.R.I., M.M.R. and K.M.M. All authors have read and agreed to the published version of the manuscript.

Funding: This research received no external funding.

Institutional Review Board Statement: Not applicable.

Informed Consent Statement: Not applicable.

Data Availability Statement: Not applicable.

Conflicts of Interest: The authors declare no conflict of interest.

\section{References}

1. Beza, M.; Bongiorno, M.; Narula, A. Impact of control loops on the passivity properties of grid-forming converters with fault-ride through capability. Energies 2021, 14, 6036. [CrossRef]

2. Ray, I. Review of impedance-based analysis methods applied to grid-forming inverters in inverter-dominated grids. Energies 2021, 14, 2686. [CrossRef]

3. Milano, F.; Dörfler, F.; Hug, G.; Hill, D.J.; Verbič, G. Foundations and challenges of low-inertia systems. In Proceedings of the 2018 Power Systems Computation Conference (PSCC), Dublin, Ireland, 11-15 June 2018; pp. 1-25. 
4. Hernández, J.C.; Bueno, P.G.; Sanchez-Sutil, F. Enhanced utility-scale photovoltaic units with frequency support functions and dynamic grid support for transmission systems. IET Renew. Power Gener. 2017, 11, 361-372. [CrossRef]

5. Pawar, B.; Batzelis, E.; Chakrabarti, S.; Pal, B.C. Grid-forming control for solar PV systems with power reserves. IEEE Trans. Sustain. Energy 2021, 12, 1947-1959. [CrossRef]

6. Guo, C.; Yang, S.; Liu, W.; Zhao, C.; Hu, J. Small-signal stability enhancement approach for VSC-HVDC system under weak AC grid conditions based on single-input single-output transfer function model. IEEE Trans. Power Deliv. 2020, 36, 1313-1323. [CrossRef]

7. Lu, S.; Xu, Z.; Xiao, L.; Jiang, W.; Bie, X. Evaluation and enhancement of control strategies for VSC stations under weak grid strengths. IEEE Trans. Power Syst. 2017, 33, 1836-1847. [CrossRef]

8. Sun, D.; Liu, H.; Gao, S.; Wu, L.; Song, P.; Wang, X. Comparison of different virtual inertia control methods for inverter-based generators. J. Mod. Power Syst. Clean Energy 2020, 8, 768-777. [CrossRef]

9. Kroposki, B.; Johnson, B.; Zhang, Y.; Gevorgian, V.; Denholm, P.; Hodge, B.-M.; Hannegan, B. Achieving a 100\% renewable grid: Operating electric power systems with extremely high levels of variable renewable energy. IEEE Power Energy Mag. 2017, 15, 61-73. [CrossRef]

10. Christensen, P.; Andersen, G.K.; Seidel, M.; Bolik, S.; Engelken, S.; Knueppel, T.; Krontiris, A.; Wuerflinger, K.; Bülo, T.; Jahn, J. High Penetration of Power Electronic Interfaced Power Sources and the Potential Contribution of Grid Forming Converters; ENTSO-E: Brussels, Belgium, 2020.

11. Lin, Y.; Eto, J.H.; Johnson, B.B.; Flicker, J.D.; Lasseter, R.H.; Villegas Pico, H.N.; Seo, G.-S.; Pierre, B.J.; Ellis, A. Research Roadmap on Grid-Forming Inverters; National Renewable Energy Laboratory (NREL): Golden, CO, USA, 2020.

12. Pattabiraman, D.; Lasseter, R.; Jahns, T. Comparison of grid following and grid forming control for a high inverter penetration power system. In Proceedings of the 2018 IEEE Power \& Energy Society General Meeting (PESGM), Portland, OR, USA, 5-10 August 2018; pp. 1-5.

13. Tayyebi, A.; Groß, D.; Anta, A.; Kupzog, F.; Dörfler, F. Frequency stability of synchronous machines and grid-forming power converters. IEEE J. Emerg. Sel. Top. Power Electron. 2020, 8, 1004-1018. [CrossRef]

14. Pattabiraman, D.; Lasseter, R.H.; Jahns, T.M. Short-term voltage stability of power systems with high inverter penetration under small disturbances. In Proceedings of the 2019 IEEE Power \& Energy Society General Meeting (PESGM), Atlanta, GA, USA, 4-8 August 2019; pp. 1-5.

15. Unruh, P.; Nuschke, M.; Strauß, P.; Welck, F. Overview on grid-forming inverter control methods. Energies 2020, 13, 2589. [CrossRef]

16. Awal, M.; Yu, H.; Husain, I.; Yu, W.; Lukic, S.M. Selective harmonic current rejection for virtual oscillator controlled grid-forming voltage source converters. IEEE Trans. Power Electron. 2020, 35, 8805-8818. [CrossRef]

17. Fang, J.; Li, H.; Tang, Y.; Blaabjerg, F. On the inertia of future more-electronics power systems. IEEE J. Emerg. Sel. Top. Power Electron. 2018, 7, 2130-2146. [CrossRef]

18. Qi, Y.; Deng, H.; Liu, X.; Tang, Y. Synthetic inertia control of grid-connected inverter considering the synchronization dynamics. IEEE Trans. Power Electron. 2021, 37, 1411-1421. [CrossRef]

19. Jiang, Y.; Bernstein, A.; Vorobev, P.; Mallada, E. Grid-forming frequency shaping control. arXiv 2020, arXiv:2009.06707.

20. Zhang, W.; Remon, D.; Rodriguez, P. Frequency support characteristics of grid-interactive power converters based on the synchronous power controller. IET Renew. Power Gener. 2017, 11, 470-479. [CrossRef]

21. Zhong, Q.-C.; Nguyen, P.-L.; Ma, Z.; Sheng, W. Self-synchronized synchronverters: Inverters without a dedicated synchronization unit. IEEE Trans. Power Electron. 2013, 29, 617-630. [CrossRef]

22. Qi, Y.; Yang, T.; Fang, J.; Tang, Y.; Potti, K.R.R.; Rajashekara, K. Grid inertia support enabled by smart loads. IEEE Trans. Power Electron. 2020, 36, 947-957. [CrossRef]

23. Fang, J.; Tang, Y.; Li, H.; Li, X. A battery/ultracapacitor hybrid energy storage system for implementing the power management of virtual synchronous generators. IEEE Trans. Power Electron. 2017, 33, 2820-2824. [CrossRef]

24. Liu, H.; Zhang, C.; Peng, X.; Zhang, S. Configuration of an energy storage system for primary frequency reserve and inertia response of the power grid. IEEE Access 2021, 9, 41965-41975. [CrossRef]

25. Heydari, R.; Savaghebi, M.; Blaabjerg, F. Fast frequency control of low-inertia hybrid grid utilizing extended virtual synchronous machine. In Proceedings of the 2020 11th Power Electronics, Drive Systems, and Technologies Conference (PEDSTC), Tehran, Iran, 4-6 February 2020; pp. 1-5.

26. Noris, L.; Rueda, J.; Rakhshani, E.; Korai, A.W. Power system black-start and restoration with high share of power-electronic converters. In Proceedings of the 2019 IEEE Power \& Energy Society General Meeting (PESGM), Atlanta, GA, USA, 4-8 August 2019; pp. 1-5.

27. Alassi, A.; Ahmed, K.; Egea-Alvarez, A.; Ellabban, O. Performance evaluation of four grid-forming control techniques with soft black-start capabilities. In Proceedings of the 2020 9th International Conference on Renewable Energy Research and Application (ICRERA), Glasgow, UK, 27-30 September 2020; pp. 221-226.

28. Alassi, A.; Ahmed, K.; Egea-Alvarez, A.; Foote, C. Modified grid-forming converter control for black-start and gridsynchronization applications. In Proceedings of the 2021 56th International Universities Power Engineering Conference (UPEC), Middlesbrough, UK, 31 August-3 September 2021; pp. 1-5. 
29. Korai, A.W.; Rakhshani, E.; Adabi, M.E.; Torres, J.L.R.; van der Meijden, M.A. Modelling and simulation of wind turbines with grid forming direct voltage control and black-start capability. In Modelling and Simulation of Power Electronic Converter Dominated Power Systems in PowerFactory; Springer: Cham, Switzerland, 2021; pp. 245-268.

30. Shrestha, A.; Gonzalez-Longatt, F. Frequency stability issues and research opportunities in converter dominated power system. Energies 2021, 14, 4184. [CrossRef]

31. Wang, X.; Chen, L.; Sun, D.; Zhang, L.; Nian, H. A modified self-synchronized synchronverter in unbalanced power grids with balanced currents and restrained power ripples. Energies 2019, 12, 923. [CrossRef]

32. Kundur, P.; Paserba, J.; Ajjarapu, V.; Andersson, G.; Bose, A.; Cañizares, C.; Hatziargyriou, N.; Hill, D.; Stankovic, A.; Taylor, C.; et al. Definition and classification of power system stability. IEEE Trans. Power Syst. 2004, 19, 1387-1401.

33. Power System Dynamic Performance Committee (PSDP). Stability Definitions and Characterization of Dynamic Behavior in Systems with High Penetration of Power Electronic Interfaced Technologies; Technical Report PS-TR77; IEEE PES: Piscataway, NJ, USA, 2020.

34. Taul, M.G.; Wang, X.; Davari, P.; Blaabjerg, F. An overview of assessment methods for synchronization stability of grid-connected converters under severe symmetrical grid faults. IEEE Trans. Power Electron. 2019, 34, 9655-9670. [CrossRef]

35. Taul, M.G.; Wang, X.; Davari, P.; Blaabjerg, F. Current limiting control with enhanced dynamics of grid-forming converters during fault conditions. IEEE J. Emerg. Sel. Top. Power Electron. 2019, 8, 1062-1073. [CrossRef]

36. Rosso, R.; Wang, X.; Liserre, M.; Lu, X.; Engelken, S. Grid-forming converters: Control approaches, grid-synchronization, and future trends-A review. IEEE Open J. Ind. Appl. 2021, 2, 93-109. [CrossRef]

37. Denis, G.; Prevost, T.; Debry, M.S.; Xavier, F.; Guillaud, X.; Menze, A. The migrate project: The challenges of operating a transmission grid with only inverter-based generation. A grid-forming control improvement with transient current-limiting control. IET Renew. Power Gener. 2018, 12, 523-529. [CrossRef]

38. Huang, L.; Xin, H.; Wang, Z.; Zhang, L.; Wu, K.; Hu, J. Transient stability analysis and control design of droop-controlled voltage source converters considering current limitation. IEEE Trans. Smart Grid 2017, 10, 578-591. [CrossRef]

39. Shi, K.; Song, W.; Xu, P.; Liu, R.; Fang, Z.; Ji, Y. Low-voltage ride-through control strategy for a virtual synchronous generator based on smooth switching. IEEE Access 2017, 6, 2703-2711. [CrossRef]

40. Wu, H.; Wang, X. Design-oriented transient stability analysis of PLL-synchronized voltage-source converters. IEEE Trans. Power Electron. 2019, 35, 3573-3589. [CrossRef]

41. Shi, K.; Ye, H.; Xu, P.; Zhao, D.; Jiao, L. Low-voltage ride through control strategy of virtual synchronous generator based on the analysis of excitation state. IET Gener. Transm. Distrib. 2018, 12, 2165-2172. [CrossRef]

42. Piya, P.; Ebrahimi, M.; Karimi-Ghartemani, M.; Khajehoddin, S.A. Fault ride-through capability of voltage-controlled inverters. IEEE Trans. Ind. Electron. 2018, 65, 7933-7943. [CrossRef]

43. Lu, X.; Wang, J.; Guerrero, J.M.; Zhao, D. Virtual-impedance-based fault current limiters for inverter dominated AC microgrids. IEEE Trans. Smart Grid 2016, 9, 1599-1612. [CrossRef]

44. Shuai, Z.; Shen, C.; Liu, X.; Li, Z.; Shen, Z.J. Transient angle stability of virtual synchronous generators using Lyapunov's direct method. IEEE Trans. Smart Grid 2018, 10, 4648-4661. [CrossRef]

45. Pan, D.; Wang, X.; Liu, F.; Shi, R. Transient stability of voltage-source converters with grid-forming control: A design-oriented study. IEEE J. Emerg. Sel. Top. Power Electron. 2019, 8, 1019-1033. [CrossRef]

46. $\mathrm{Wu}, \mathrm{H}$.; Wang, X. Design-oriented transient stability analysis of grid-connected converters with power synchronization control. IEEE Trans. Ind. Electron. 2018, 66, 6473-6482. [CrossRef]

47. Bottrell, N.; Green, T.C. Comparison of current-limiting strategies during fault ride-through of inverters to prevent latch-up and wind-up. IEEE Trans. Power Electron. 2013, 29, 3786-3797. [CrossRef]

48. Chen, J.; Prystupczuk, F.; O'Donnell, T. Use of voltage limits for current limitations in grid-forming converters. CSEE J. Power Energy Syst. 2020, 6, 259-269.

49. Awal, M.; Husain, I. Transient stability assessment for current constrained and unconstrained fault ride-through in virtual oscillator controlled converters. IEEE J. Emerg. Sel. Top. Power Electron. 2021, 9, 6935-6946. [CrossRef]

50. Rokrok, E.; Qoria, T.; Bruyere, A.; Francois, B.; Guillaud, X. Transient stability assessment and enhancement of grid-forming converters embedding current reference saturation as current limiting strategy. IEEE Trans. Power Syst. 2021. [CrossRef]

51. Rosso, R.; Engelken, S.; Liserre, M. On the implementation of an FRT strategy for grid-forming converters under symmetrical and asymmetrical grid faults. IEEE Trans. Ind. Appl. 2021, 57, 4385-4397. [CrossRef]

52. Qoria, T.; Gruson, F.; Colas, F.; Denis, G.; Prevost, T.; Guillaud, X. Critical clearing time determination and enhancement of grid-forming converters embedding virtual impedance as current limitation algorithm. IEEE J. Emerg. Sel. Top. Power Electron. 2019, 8, 1050-1061. [CrossRef]

53. Me, S.P.; Zabihi, S.; Blaabjerg, F.; Bahrani, B. Adaptive virtual resistance for post-fault oscillation damping with grid-forming control. IEEE Trans. Power Electron. 2021, 37, 3813-3824. [CrossRef]

54. Wu, H.; Wang, X. A mode-adaptive power-angle control method for transient stability enhancement of virtual synchronous generators. IEEE J. Emerg. Sel. Top. Power Electron. 2020, 8, 1034-1049. [CrossRef]

55. Chen, M.; Zhou, D.; Blaabjerg, F. Enhanced transient angle stability control of grid-forming converter based on virtual synchronous generator. IEEE Trans. Ind. Electron. 2021. [CrossRef]

56. Xiong, X.; Wu, C.; Cheng, P.; Blaabjerg, F. An optimal damping design of virtual synchronous generators for transient stability enhancement. IEEE Trans. Power Electron. 2021, 36, 11026-11030. [CrossRef] 
57. Wang, X.; Blaabjerg, F. Harmonic stability in power electronic-based power systems: Concept, modeling, and analysis. IEEE Trans. Smart Grid 2018, 10, 2858-2870. [CrossRef]

58. Huang, L.; Xin, H.; Yang, H.; Wang, Z.; Xie, H. Interconnecting very weak AC systems by multiterminal VSC-HVDC links with a unified virtual synchronous control. IEEE J. Emerg. Sel. Top. Power Electron. 2018, 6, 1041-1053. [CrossRef]

59. Yang, C.; Huang, L.; Xin, H.; Ju, P. Placing grid-forming converters to enhance small signal stability of PLL-integrated power systems. IEEE Trans. Power Syst. 2020, 36, 3563-3573. [CrossRef]

60. Rosso, R.; Cassoli, J.; Buticchi, G.; Engelken, S.; Liserre, M. Robust stability analysis of LCL filter based synchronverter under different grid conditions. IEEE Trans. Power Electron. 2018, 34, 5842-5853. [CrossRef]

61. Rodríguez-Cabero, A.; Roldán-Pérez, J.; Prodanovic, M. Virtual impedance design considerations for virtual synchronous machines in weak grids. IEEE J. Emerg. Sel. Top. Power Electron. 2019, 8, 1477-1489. [CrossRef]

62. Baltas, G.N.; Lai, N.B.; Marin, L.; Tarraso, A.; Rodriguez, P. Grid-forming power converters tuned through artificial intelligence to damp subsynchronous interactions in electrical grids. IEEE Access 2020, 8, 93369-93379. [CrossRef]

63. Anderson, P.M.; Farmer, R.G. Series Compensation of Power Systems; PBLSH: Encinitas, CA, USA, 1996.

64. Ebrahimzadeh, E.; Blaabjerg, F.; Wang, X.; Bak, C.L. Harmonic stability and resonance analysis in large PMSG-based wind power plants. IEEE Trans. Sustain. Energy 2018, 9, 12-23. [CrossRef]

65. Yu, M.; Roscoe, A.J.; Booth, C.D.; Dyśko, A.; Ierna, R.; Zhu, J.; Urdal, H. Use of an inertia-less Virtual Synchronous Machine within future power networks with high penetrations of converters. In Proceedings of the Power Systems Computation Conference (PSCC), Genoa, Italy, 20-24 June 2016.

66. Roscoe, A.J.; Yu, M.; Dyśko, A.; Booth, C.; Ierna, R.; Zhu, J.; Urdal, H. A VSM (virtual synchronous machine) convertor control model suitable for RMS studies for resolving system operator/owner challenges. In Proceedings of the 15th Wind Integration Workshop, Vienna, Austria, 15-17 November 2016.

67. Li, G.; Chen, Y.; Luo, A.; He, Z.; Wang, H.; Zhu, Z.; Wu, W.; Zhou, L. Analysis and mitigation of subsynchronous resonance in series-compensated grid-connected system controlled by a virtual synchronous generator. IEEE Trans. Power Electron. 2020, 35 , 11096-11107. [CrossRef]

68. Liao, Y.; Wang, X.; Liu, F.; Xin, K.; Liu, Y. Sub-synchronous control interaction in grid-forming VSCs with droop control. In Proceedings of the 2019 4th IEEE Workshop on the Electronic Grid (eGRID), Xiamen, China, 11-14 November 2019; pp. 1-6.

69. Lai, N.B.; Baltas, G.N.; Rodriguez, P. Multi-rotor virtual machine for grid-forming converter to damp sub-synchronous resonances IEEE Access 2021, 9, 128178-128187. [CrossRef]

70. Peng, Y.; Wang, Y.; Liu, Y.; Yu, P.; Shu, S.; Lei, W. A full sequence impedance modelling and stability analysis of the virtual synchronous generator with inner loops. IET Renew. Power Gener. 2021, 15, 397-408. [CrossRef]

71. Zhang, X.; Zhanga, H.; Li, M.; Guo, Z.; Hu, Y.; Chen, Q.; Liu, X.; Lib, F. Analysis of dynamic power angle oscillation and its suppression strategy for the droop-controlled grid-connected inverter. IEEE J. Emerg. Sel. Top. Power Electron. 2021, 9, 5718-5731. [CrossRef]

72. Wang, F.; Zhang, L.; Feng, X.; Guo, H. An adaptive control strategy for virtual synchronous generator. IEEE Trans. Ind. Appl. 2018, 54, 5124-5133. [CrossRef]

73. Li, C.; Yang, Y.; Cao, Y.; Wang, L.; Dragicevic, T.; Blaabjerg, F. Frequency and voltage stability analysis of grid-forming virtual synchronous generator attached to weak grid. IEEE J. Emerg. Sel. Top. Power Electron. 2020. [CrossRef]

74. Matevosyan, J.; Badrzadeh, B.; Prevost, T.; Quitmann, E.; Ramasubramanian, D.; Urdal, H.; Achilles, S.; MacDowell, J.; Huang, S.H.; Vital, V. Grid-forming inverters: Are they the key for high renewable penetration? IEEE Power Energy Mag. 2019, 17, 89-98. [CrossRef]

75. Zhou, K.; Yang, Y.; Blaabjerg, F.; Wang, D. Optimal selective harmonic control for power harmonics mitigation. IEEE Trans. Ind. Electron. 2014, 62, 1220-1230. [CrossRef]

76. Awal, M.; Husain, I.; Yu, W. Predictive current control for stabilizing power electronics based AC power systems. In Proceedings of the 2017 IEEE Energy Conversion Congress and Exposition (ECCE), Cincinnati, OH, USA, 1-5 October 2017; pp. 4634-4641.

77. Awal, M.; Yu, H.; Della Flora, L.; Yu, W.; Lukic, S.; Husain, I. Observer based admittance shaping for resonance damping in voltage source converters with LCL filter. In Proceedings of the 2019 IEEE Energy Conversion Congress and Exposition (ECCE), Baltimore, MD, USA, 29 September-3 October 2019; pp. 4455-4462.

78. Awal, M.; Yu, W.; Husain, I. Passivity-based predictive-resonant current control for resonance damping in LCL-equipped VSCs. IEEE Trans. Ind. Appl. 2019, 56, 1702-1713. [CrossRef]

79. Liang, X.; Andalib-Bin-Karim, C. Harmonics and mitigation techniques through advanced control in grid-connected renewable energy sources: A review. IEEE Trans. Ind. Appl. 2018, 54, 3100-3111. [CrossRef]

80. Mukundan, N.; Singh, Y.; Naqvi, S.B.Q.; Singh, B.; Pychadathil, J. Multi-objective solar power conversion system with MGI control for grid integration at adverse operating conditions. IEEE Trans. Sustain. Energy 2020, 11, 2901-2910.

81. Barragán-Villarejo, M.; Mauricio, J.M.; Olives-Camps, J.C.; Matas-Díaz, F.J.; de Paula García-López, F.; Maza-Ortega, J.M Harmonic and Imbalance Compensation in Grid-Forming VSC. In Proceedings of the 2020 IEEE International Conference on Industrial Technology (ICIT), Buenos Aires, Argentina, 26-28 February 2020; pp. 757-762.

82. Munir, S.; Li, Y.W. Residential distribution system harmonic compensation using PV interfacing inverter. IEEE Trans. Smart Grid 2013, 4, 816-827. [CrossRef] 
83. Han, Y.; Shen, P.; Zhao, X.; Guerrero, J.M. An enhanced power sharing scheme for voltage unbalance and harmonics compensation in an islanded AC microgrid. IEEE Trans. Energy Convers. 2016, 31, 1037-1050. [CrossRef]

84. De, D.; Ramanarayanan, V. Decentralized parallel operation of inverters sharing unbalanced and nonlinear loads. IEEE Trans. Power Electron. 2010, 25, 3015-3025. [CrossRef]

85. Sreekumar, P.; Khadkikar, V. A new virtual harmonic impedance scheme for harmonic power sharing in an islanded microgrid. IEEE Trans. Power Deliv. 2015, 31, 936-945. [CrossRef]

86. Chen, J.; Wang, L.; Diao, L.; Du, H.; Liu, Z. Distributed auxiliary inverter of urban rail train—Load sharing control strategy under complicated operation condition. IEEE Trans. Power Electron. 2015, 31, 2518-2529. [CrossRef]

87. Han, H.; Hou, X.; Yang, J.; Wu, J.; Su, M.; Guerrero, J.M. Review of power sharing control strategies for islanding operation of AC microgrids. IEEE Trans. Smart Grid 2015, 7, 200-215. [CrossRef]

88. Sreekumar, P.; Khadkikar, V. Direct control of the inverter impedance to achieve controllable harmonic sharing in the islanded microgrid. IEEE Trans. Ind. Electron. 2016, 64, 827-837. [CrossRef]

89. Guerrero, J.M.; Matas, J.; de Vicuna, L.G.; Castilla, M.; Miret, J. Decentralized control for parallel operation of distributed generation inverters using resistive output impedance. IEEE Trans. Ind. Electron. 2007, 54, 994-1004. [CrossRef]

90. Vandoorn, T.; Meersman, B.; De Kooning, J.; Vandevelde, L. Controllable harmonic current sharing in islanded microgrids: DG units with programmable resistive behavior toward harmonics. IEEE Trans. Power Deliv. 2012, 27, 831-841. [CrossRef]

91. Li, Y.W.; He, J. Distribution system harmonic compensation methods: An overview of DG-interfacing inverters. IEEE Ind. Electron. Mag. 2014, 8, 18-31. [CrossRef]

92. Teodorescu, R.; Blaabjerg, F.; Liserre, M. Proportional-resonant controllers. A new breed of controllers suitable for grid-connected voltage-source converters. J. Electr. Eng. 2006, 6, 6.

93. Pogaku, N.; Green, T. Harmonic mitigation throughout a distribution system: A distributed-generator-based solution. IEE Proc.-Gener. Transm. Distrib. 2006, 153, 350-358. [CrossRef]

94. He, J.; Li, Y.W. Generalized microgrid harmonic compensation strategies using DG unit interfacing converters. In Proceedings of the IECON 2012 - 38th Annual Conference on IEEE Industrial Electronics Society, Montreal, QC, Canada, 25-28 October 2012; pp. 3419-3424.

95. He, J.; Li, Y.W.; Munir, M.S. A flexible harmonic control approach through voltage-controlled DG-grid interfacing converters. IEEE Trans. Ind. Electron. 2011, 59, 444-455. [CrossRef]

96. Chen, X.; Ruan, X.; Yang, D.; Zhao, W.; Jia, L. Injected grid current quality improvement for a voltage-controlled grid-connected inverter. IEEE Trans. Power Electron. 2017, 33, 1247-1258. [CrossRef]

97. Lou, G.; Yang, Q.; Gu, W.; Zhang, J. An improved control strategy of virtual synchronous generator under symmetrical grid voltage sag. Int. J. Electr. Power Energy Syst. 2020, 121, 106093. [CrossRef]

98. Wu, H.; Ruan, X.; Yang, D.; Chen, X.; Zhao, W.; Lv, Z.; Zhong, Q.-C. Small-signal modeling and parameters design for virtual synchronous generators. IEEE Trans. Ind. Electron. 2016, 63, 4292-4303. [CrossRef]

99. Zhong, Q.-C.; Weiss, G. Synchronverters: Inverters that mimic synchronous generators. IEEE Trans. Ind. Electron. 2010, 58, 1259-1267. [CrossRef]

100. Sun, J. Impedance-based stability criterion for grid-connected inverters. IEEE Trans. Power Electron. 2011, 26, 3075-3078. [CrossRef]

101. Yang, W.; Wang, M.; Aziz, S.; Kharal, A.Y. Magnitude-reshaping strategy for harmonic suppression of VSG-based inverter under weak grid. IEEE Access 2020, 8, 184399-184413. [CrossRef]

102. Asrari, A.; Mustafa, M.; Ansari, M.; Khazaei, J. Impedance analysis of virtual synchronous generator-based vector controlled converters for weak AC grid integration. IEEE Trans. Sustain. Energy 2019, 10, 1481-1490. [CrossRef]

103. Lou, G.; Yang, Q.; Gu, W.; Quan, X.; Guerrero, J.M.; Li, S. Analysis and design of hybrid harmonic suppression scheme for VSG considering nonlinear loads and distorted grid. IEEE Trans. Energy Convers. 2021, 36, 3096-3107. [CrossRef]

104. Zhou, L.; Liu, S.; Chen, Y.; Yi, W.; Wang, S.; Zhou, X.; Wu, W.; Zhou, J.; Xiao, C.; Liu, A. Harmonic current and inrush fault current coordinated suppression method for VSG under non-ideal grid condition. IEEE Trans. Power Electron. 2020, 36, 1030-1042. [CrossRef]

105. Hu, Y.; Shao, Y.; Yang, R.; Long, X.; Chen, G. A configurable virtual impedance method for grid-connected virtual synchronous generator to improve the quality of output current. IEEE J. Emerg. Sel. Top. Power Electron. 2019, 8, 2404-2419. [CrossRef]

106. Mojiri, M.; Karimi-Ghartemani, M.; Bakhshai, A. Time-domain signal analysis using adaptive notch filter. IEEE Trans. Signal Processing 2006, 55, 85-93. [CrossRef]

107. Ketabi, A.; Farshadnia, M.; Malekpour, M.; Feuillet, R. A new control strategy for active power line conditioner (APLC) using adaptive notch filter. Int. J. Electr. Power Energy Syst. 2013, 47, 31-40. [CrossRef]

108. Chilipi, R.S.R.; Al Sayari, N.; Al Hosani, K.H.; Beig, A.R. Adaptive notch filter-based multipurpose control scheme for gridinterfaced three-phase four-wire DG inverter. IEEE Trans. Ind. Appl. 2017, 53, 4015-4027. [CrossRef]

109. Singh, B.; Kant, K.; Arya, S.R. Notch filter-based fundamental frequency component extraction to control distribution static compensator for mitigating current-related power quality problems. IET Power Electron. 2015, 8, 1758-1766. [CrossRef]

110. Kewat, S.; Singh, B. Modified amplitude adaptive control algorithm for power quality improvement in multiple distributed generation system. IET Power Electron. 2019, 12, 2321-2329. [CrossRef]

111. Schaumann, R.; Mac Elwyn Van Valkenburg, X.; Xiao, H. Design of Analog Filters; Oxford University Press: New York, NY, USA, 2001; Volume 1. 
112. Radwan, A.G.; Elwakil, A.S.; Soliman, A.M. On the generalization of second-order filters to the fractional-order domain. J. Circ. Syst. Comput. 2009, 18, 361-386. [CrossRef]

113. Adhikary, A.; Sen, S.; Biswas, K. Practical realization of tunable fractional order parallel resonator and fractional order filters. IEEE Trans. Circ. Syst. I Regul. Pap. 2016, 63, 1142-1151. [CrossRef]

114. Ahmadi, P.; Maundy, B.; Elwakil, A.S.; Belostotski, L. High-quality factor asymmetric-slope band-pass filters: A fractional-order capacitor approach. IET Circ. Devices Syst. 2012, 6, 187-197. [CrossRef]

115. Bošković, M.; Šekara, T.B.; Rapaić, M.R.; Lutovac, B.; Daković, M.; Govedarica, V. Novel band-pass and notch filter with dynamic damping of fractional order. In Proceedings of the 2017 25th Telecommunication Forum (TELFOR), Belgrade, Serbia, 21-22 November 2017; pp. 1-4.

116. Badoni, M.; Singh, A.; Pandey, S.; Singh, B. Fractional order notch filter for grid-connected solar pv system with power quality improvement. IEEE Trans. Ind. Electron. 2021, 69, 429-439. [CrossRef]

117. Jain, V.; Singh, B. A multiple improved notch filter-based control for a single-stage PV system tied to a weak grid. IEEE Trans. Sustain. Energy 2018, 10, 238-247. [CrossRef]

118. Kalla, U.K.; Kaushik, H.; Singh, B.; Kumar, S. Adaptive control of voltage source converter based scheme for power quality improved grid-interactive solar PV-battery system. IEEE Trans. Ind. Appl. 2019, 56, 787-799. [CrossRef]

119. Singh, B.; Chandra, A.; Al-Haddad, K. Power Quality: Problems and Mitigation Techniques; John Wiley \& Sons: Hoboken, NJ, USA, 2014.

120. Lopes, C.G.; Sayed, A.H. Diffusion least-mean squares over adaptive networks. In Proceedings of the 2007 IEEE International Conference on Acoustics, Speech and Signal Processing-ICASSP'07, Honolulu, HI, USA, 15-20 April 2007; pp. III-917-III-920.

121. Sayed, A.H.; Lopes, C.G. Distributed processing over adaptive networks. In Proceedings of the 2007 9th International Symposium on Signal Processing and Its Applications, Sharjah, United Arab Emirates, 12-15 February 2007; pp. 1-3.

122. Hajiabadi, M.; Zamiri-Jafarian, H. Distributed adaptive LMF algorithm for sparse parameter estimation in Gaussian mixture noise. In Proceedings of the 7'th International Symposium on Telecommunications (IST'2014), Tehran, Iran, 9-11 September 2014; pp. 1046-1049.

123. Singh, A.K.; Kumar, S.; Singh, B. Solar PV energy generation system interfaced to three phase grid with improved power quality. IEEE Trans. Ind. Electron. 2019, 67, 3798-3808. [CrossRef] 